CAHIER DE RECHERCHE \#1203E

Département de science économique

Faculté des sciences sociales

Université d'Ottawa
WORKING PAPER \#1203E

Department of Economics

Faculty of Social Sciences

University of Ottawa

\title{
Campaign Contributions over CEOs’ Careers ${ }^{*}$
}

\author{
Adam R. Fremeth $^{\dagger}$, Brian Kelleher Richter ${ }^{\ddagger}$ and Brandon Schaufele ${ }^{\S}$
}

January 2012

\footnotetext{
* This paper benefited from the insightful comments of Tony Frost, Guy Holburn, Edward Leamer and Nicholas Rivers.

${ }^{\dagger}$ Richard Ivey School of Business, University of Western Ontario, 1151 Richmond Street N., London, Ontario, Canada, N6A 3K7; afremeth@ivey.uwo.ca.

${ }^{\ddagger}$ Richard Ivey School of Business, University of Western Ontario, 1151 Richmond Street N., London, Ontario, Canada, N6A 3K7; brichter@ivey.uwo.ca.

$\S$ Department of Economics, University of Ottawa, 55 Laurier E., Ottawa, Ontario, Canada, K1N 6N5; Email: brandon.schaufele@uottawa.ca.
} 


\begin{abstract}
Individuals dominate money in politics, accounting for over $90 \%$ of campaign contributions, but studies of individuals' giving are scarce. We show that individuals increase their personal contributions dramatically when they assume leadership roles at organizations such as labor unions, non-profits, and firms. Using a newly constructed dataset that focuses on personal contributions, we exploit variation in the leadership status of all 2,198 individuals who were S\&P 500 CEOs at any point between 1991 and 2008 to identify a \$4,000 jump in personal political giving when individuals become CEOs. Despite giving more money to more candidates, more political action committees (PACs), and more parties, active CEOs' partisan orientations remain largely unchanged. Falsification tests of an underlying identification assumption demonstrate that these patterns hold whether an individual is promoted to CEO internally or appointed externally. While some fraction of CEOs' contributions can be attributed to longstanding preferences, willingness, and ability to contribute, the striking change in behavior we identify cannot be explained by these factors alone.
\end{abstract}

Key words: Campaign Contributions, CEOs, Leaders, Personnel Economics, PACs.

JEL Classification: D72, H89, K00, M59.

\title{
Résumé
}

Les individus dominent l'argent en politique, ce qui représente plus de $90 \%$ des contributions à la campagne, mais les études des dons des individus sont rares. Nous montrons que les individus augmentent leur contribution personnelle de façon spectaculaire quand ils assument des rôles de leadership dans des organisations comme les syndicats, les organismes sans but lucratif et les entreprises. En utilisant un ensemble de données nouvellement construit qui se concentre sur les contributions personnelles, nous exploitons la variation dans le statut de leader de toutes les 2198 personnes qui ont été S \& P 500 chef de la direction à n'importe quel point entre 1991 et 2008 afin d'identifier un saut de 4000 \$ dans les dons politiques personnels quand les individus deviennent chef de la direction. Malgré donnant plus d'argent à plusieurs candidats, comités d'action politique (PAC), et parties, les orientations partisanes des chefs de la direction actifs demeurent largement inchangées. Tests de falsification d'une hypothèse d'identification qui sous-tend démontrent que ces modèles détiennent si un individu est promu chef de la direction de l'interne ou désigné de l'extérieur. Alors qu'une certaine fraction des contributions de chef de la direction peut être attribuée aux préférences et la capacité de contribuer, le changement frappant dans le comportement nous identifions ne peut pas être expliquée par ces facteurs à eux seuls.

Mots clés: contributions à la campagne, des chef de la direction, des dirigeants, l'économie de personnel, PACs.

Classification JEL: D72, H89, K00, M59. 


\section{Introduction}

In 2008, Americans spent over $\$ 5.29 B$ on political campaign contributions. Media coverage of, and the academic literature on, campaign contributions tend to focus on Political Action Committee (PAC) contributions, and in particular those from corporate-linked PACs (Milyo, Primo, and Groseclose 2000; Ansolabehere, Snowberg, and Snyder 2005). Nevertheless, contributions from PACs linked to corporations, labor unions, or other interest groups, accounted for only $\$ 0.41 \mathrm{~B}$ of the total. Individuals' personal contributions to candidates and parties, which garner less attention, accounted for more than $90 \%$ of the money or $\$ 4.87 \mathrm{~B}$ of the total contributions made. This research adds to a growing literature on the largest, yet most neglected element of campaign contributions: individual giving. Studies touching on individuals' campaign contributions include those by Burris (2001), Gupta and Swenson (2003), Francia, et. al (2003), Gordon, Hafer, and Landa (2007), Joulfaian and Marlow (1991), and Ovtchinnikov and Pantaleoni (forthcoming).

Individuals' campaign contributions are determined, in part, by their personal relationships, ideology, and strategic motives (Francia, et. al 2003). In addition to individuals' long-standing preferences, contribution patterns could also be driven by their shorter-lived roles in organizations such as firms, non-profits, and labor unions. Particular organizational roles may induce individuals to undertake political activities that are not perfectly aligned with their private tastes; however, the interaction between private preferences and one's role within an organization has yet to be explored. This paper investigates this interaction. While in principal any role an individual plays at any type of organization could be linked to their political contribution patterns, we focus on individuals who play leadership roles.

When people become leaders of organizations, they set cultural norms and serve as the 
public face of their organizations. Moreover, leaders may feel obligated to alter their personal behavior to suit what they believe is best for their organization. These factors, among others, may explain changes in individuals' political contribution patterns upon assuming leadership roles in organizations.

Figure 1 provides illustrative examples of the contribution patterns of representative individuals who held leadership positions at various types of organizations during their careers. For individuals who become leaders of each type of organization-labor union, non-profit, and business - we see that when they assume leadership roles, their personal campaign contribution patterns change. Both the frequency and volume increases. In panel A, we see the giving pattern for Michael McNally, who served as the President of his labor union, the National Air Traffic Controllers Association (NATCA) from September 1997 to September 2000. Prior to his election to the Presidency, McNally worked as an air traffic controller in New York and had been active in less visible roles in the labor union, but never made campaign contributions; once McNally assumed the Presidency, however, he began making regular campaign contributionsonly to return to his prior pattern of no contributions once he left the labor union's leadership position to return to his prior job. In Panel B, we see the giving patterns of Reynold Levy, who has served as the President of a high profile non-profit, New York's Lincoln Center for the Performing Arts, since March 2002. Prior to being selected as the President of Lincoln Center he worked in government relations for AT\&T, nevertheless he made more significant contributions in his later role as the leader of the non-profit. Finally, in Panel C, we see the giving patterns of Paul M. Anderson, who served as the CEO for two different S\&P 500 energy companies, PanEnergy, from April 1995 through March 1998, and Duke Energy, from November 2003 through January 2007. While Anderson demonstrated interest in political giving prior to his 
initial appointment as CEO, both the intensity and frequency of his campaign contributions increased during the periods when he served as a CEO of an S\&P 500 firm.

\section{$<$ Insert Figure 1 Here>}

While we would ideally conduct a broad and well-identified empirical analysis of the political contributions of individuals who serve in leadership roles at various types of organizations, we limit our analysis to business leaders. Our analysis focuses specifically on the 2,198 individuals who served as S\&P 500 CEOs at any point during the 1991-2008 timeframe because these are individuals for whom we can collect high quality data and because it produces a sample for which statistical identification assumptions can be satisfied.

The political activities of high profile CEOs - who control a relatively large share of the economy's resources - occupy a unique place in the public discourse on US electoral politics. Media outlets elevate some CEOs to "superstar" status (Tate and Malmendier 2009) and pundits frequently argue about the business community's influence in politics. Nevertheless, the intersection between CEOs' private activities and the business community's influence in politics has received relatively scant attention. Many of the basic facts about CEOs' personal campaign contributions are still unknown. Knowing the share of S\&P 500 CEOs that give, the average dollar amount they give, and the partisan composition of their contributions would help if we ever hope to understand even the basic facts about these individuals' roles in political campaigns. ${ }^{1}$

Excluding non-business leaders from our analysis helps ensure reliable results from tests of our statistical hypotheses. There are at least three unique challenges with the analysis of

\footnotetext{
${ }^{1}$ Ansolabehere, deFiguieredo, and Snyder (2003) consider giving by 94 executives from 12 firms in the 1997-1998 election cycle. They find these executives gave $\$ 3,000$ to PACs and an additional $\$ 4,500$ to candidates, on average. Still, it is unknown whether their sample is representative or whether the CEOs' contributions differ systematically from non-CEOs. Gordon, Hafer, and Landa (2007) collect data on a random sub-sample of S\&P 1500 executives' giving during their tenure as leaders, but do not provide summary statistics on the giving patterns.
} 
contributions patterns for labor union and non-profit leaders that do not plague analysis of business leaders' contribution patterns. First, the data required-particularly as controls or to test alternative explanations for changing political contribution patterns - is not publicly available for labor union and non-profit leaders. Second, reverse causality concerns are intractable when considering labor union ${ }^{2}$ and non-profit leaders, ${ }^{3}$ but can be addressed within the CEO population. Third, individuals' tenures in leadership roles at both labor unions and nonprofit organizations tend to exceed the tenures of CEOs, making it difficult to observe these individuals' behavior both before and after they assumed their respective leadership positions. ${ }^{4}$

Consistent with our motivating examples displayed in Figure 1, we find that when individuals become the CEO of an S\&P 500 company, they increase their personal contributions by approximately $\$ 4,000$ in a given election cycle. This result comes from a set of econometric models that demonstrate the political behavior of active CEOs is distinct from the behavior displayed by the same individuals during their pre- and former-CEO states. Active CEOs also increase the number of contributions they make; however, their partisan orientation does not change suggesting that their underlying preferences remain constant. The observed leadership effect exists along both the intensive and extensive margins. The core results are robust to individuals' incomes, individuals' wealth tied to their firm, individual fixed effects and election-

${ }^{2}$ Individuals with aspirations to become labor union leaders need to appeal to the general union membership as these leadership positions are generally elected ones. As such, individuals may intentionally establish records of high political giving prior to running for office as a signal to union members. Similarly, they may give prior to obtaining a leadership role if they believe any established associations with sympathetic politicians will help them win their election. This implies that political giving may cause individuals to become labor union leaders because of the dynamics of the leadership selection process (which differ from the selection process for CEOs).

${ }^{3}$ Non-profit leaders are often selected because of established network of connections enables them to bring charitable donations from high profile individuals to their organizations. Hence, high-profile non-profit leaders are often chosen based on political or business, leadership positions, both of which may have been associated with higher levels of personal political contributions - so once again high levels of giving may cause individuals to become non-profit leaders. For example, Elaine Chao left her political appointments in the George H. W. Bush administration as Director of the Peace Corps and Deputy Secretary of Transportation to head the United Way nonprofit; Chao later became the Secretary of Labor under George W. Bush.

${ }^{4}$ Kaplan and Minton (2006) find that the annual turnover rate of CEOs at Fortune 500 firms equals $14.9 \%$, implying that the average tenure of a CEO is less than 7 years or approximately 3 election cycles, consistent with the 2.94 election-cycle mean tenure in our dataset. 
cycle fixed effects. Falsification tests of assumptions underlying our identification strategy further reinforce our predictions.

While our results are novel, particularly because they focus on individuals and the roles they play in organizations as determinants of personal political contributions, they can be interpreted in light of existing perspectives on campaign contributions more broadly. Existing perspectives suggest that political giving is either (i) strategic (Durden and Silberman 1976; Baron 1989; Snyder 1990; Grier, Munger, and Roberts 1994; Austen-Smith 1995, 1998; Kroszner and Stratmann 1998; Stratmann 1995, 1998; Cotton, forthcoming); (ii) representative of an agency problem as contributions are ineffectual (Chappell 1982; Keim and Zardkoohi 1988; Grenzke 1989; Wright 1990; Bebchuck and Jackson 2010; Aggarwal, Meschke, and Wang 2011; Coates 2011); or, (iii) a form of consumption (Ansolabehere, deFigueiredo, and Snyder 2003). Since we are working at the individual donor level, we do not directly test the competing organization-level hypotheses on campaign contributions. Nevertheless, our results can be interpreted as finding a middle ground between at least two of the three existing hypotheses. That is, campaign contributions could be either (i) one part consumption and one part strategy, (ii) one part consumption and one part agency problem, or (iii) a combination of consumption, strategy, and agency. Active CEOs give more when they are paid more, suggesting that campaign contributions are a normal consumption good; however, leadership roles induce individuals to give more than could be explained by increases in salary alone. This additional amount attributable to the leadership role could represent either a strategic attempt to influence policy or an agency problem if the glamor of politics interferes with individuals' duties to their organization. We discuss a number of alternative explanations consistent with individual motives rather than the typical corporate-focused ones. 
The remainder of this paper is organized as follows. Section two reviews facts on campaign contributions, explains our dataset, and presents summary statistics. Section three details our empirical approach. The fourth section contains our results. The fifth includes a discussion. Concluding comments follow in section six.

\section{Data on Individuals' Campaign Contribution}

To test our hypothesis - that when individuals become leaders of organizations, they alter their personal campaign contribution patterns - we construct a purpose-built panel dataset of all of the campaign contributions 2,198 individuals make over the nine election-cycles from 1991 to 2008. For an individual to be included in our sample they needed to have served as CEO of an S\&P 500 company at some point during that timeframe. We review laws and disclosure rules related to campaign contributions before getting into details about our dataset.

\subsection{Campaign Contribution Rules and Disclosure}

Individuals may make campaign contributions to either: (i) candidates, (ii) parties, or (iii) PACs. Most prior analyses only consider aggregate contributions rather than breakdowns to each type of political counterparty. Contributions made by individuals directly to candidates or parties differ from contributions to PACs in that individuals have complete control over which politician or political party receives their funds. ${ }^{5}$ Individuals' contributions to PACs, on the other hand, pass through a third party who determines their ultimate candidate and political party recipients. ${ }^{6}$ Despite the widely-held misconception that corporate PAC money comes directly from corporate treasuries, the truth is that all campaign contribution money comes initially from

\footnotetext{
${ }^{5}$ Which PACs an individual is legally permitted to give to is restricted. In particular, "connected PACs" linked to organizations may only accept donations from a "restricted class" of individuals as outlined in FEC Regulations $\S 114$. Individuals in this "restricted class" must have demonstrable ties to the organization with which a "connected PAC" is affiliated.

${ }^{6}$ A PAC treasurer-who is not necessarily the leader of a linked-organization, although is often a lower-ranking executive at the linked-organization-authorizes how a PAC spends its funds. PAC treasurers face limits on their spending, just like individuals face limits on how much they can give to political counterparties.
} 
individuals. ${ }^{7}$ Hence, concentrating solely on contributions that flow through PACs would be limiting.

Individuals' campaign contributions are subject to legal limits enforced by the Federal Election Commission (FEC). Table 1 displays these limits and how they evolve. These limit rules are complicated because they apply differentially not only with respect to individual transactions with each type of political counterparty, but also because they include aggregate and sub-aggregate caps. Moreover, they can change with regulation.

\section{$<$ Insert Table 1>}

The FEC also collects and makes publicly available data on campaign contributions. For each transaction greater than $\$ 200$, the candidate, party or PAC that receives the contribution is legally required to file a report with information identifying donors (including name, occupation, and address) and the amount they gave (FEC 2011). ${ }^{8}$

\subsection{Dataset Construction}

We constructed a new dataset based primarily on the publicly available FEC records and entries in the commercially available ExecuComp database. We supplemented and filled missing entries using additional information found in executives' biographies. Our dataset includes all contribution activity of all individuals who served as the CEO of any S\&P 500 firm at any point during the years 1991 through 2008. A balanced panel covers periods before, during, and after individuals' tenures as chief executive. To the authors' knowledge, no existing dataset

\footnotetext{
${ }^{7}$ Legally, campaign contributions to individual candidates from corporate treasuries have been banned since the passage of the Tillman Act in 1907. Prior to the passage of McCain-Feingold in 2002, however, "soft money" could be donated from corporate treasuries to political parties, but not to individual candidates.

${ }^{8}$ The actual information collected by the FEC is quite messy, with numerous misspellings, partial entries, etc. Moreover, there is no unique identifier for contributors, complicating researchers' ability to track whether or not any of several "John Smith" entries represent the same individual within an election cycle, let alone across election cycles. It is possible with some discretion, however, to construct unique matches and create unique identifiers for individuals with additional biographical information about particular individuals in question.
} 
provides similarly comprehensive coverage of CEOs' personal political contributions. ${ }^{9}$

Collecting the data required several steps. First, a list of relevant names along with tenure

dates for all S\&P 500 CEOs was produced. This list was generated using the ExecuComp

database and supplemented with annual report information from EDGAR and the investor

relations divisions at several firms. The second step involved matching CEOs to the tens-of-

millions of potentially relevant individual FEC transactions which were retrieved from the

Center for Responsive Politics (www.opensecrets.org, 2011). In order to connect FEC

information to the list of CEO names, a matching protocol was developed and applied on a best

efforts basis: individuals were matched based on biographical and employment information. ${ }^{10}$

Finally, we merged additional data from ExecuComp on attributes of the individuals in the

sample (e.g., salary and stock ownership) into our dataset. ${ }^{11}$

\subsection{Descriptive Statistics}

Table 2 presents summary statistics for the contributions data. It reveals several

interesting characteristics of CEOs' political giving patterns. A large majority of the 2,198

\footnotetext{
${ }^{9}$ Gordon, Hafer, and Landa (2007) collect somewhat similar data, but their timeframe is narrower (1996-2002), sample includes fewer executives (only 1,144), does not focus exclusively on CEOs, and contains data only during individuals' time as leaders such that with it behavior prior to or after serving in leadership roles is unobserved. As such, they cannot identify the causal effect of becoming a leader, but rather can observe associations between individuals' income levels and firm-linked wealth and their political giving while in leadership roles only.

${ }^{10}$ To avoid biasing the coding of matches, pervious contributions were not used as matching criteria. In the majority of cases, matches were straightforward, since CEOs names were sufficiently unique, the FEC identifying data clearly fit with individuals' biographical information, and FEC addresses matched locations of employers or known residences. For example, contributions from Warren Buffett were straightforward as his name is sufficiently unique, his primary address has always been in Nebraska, and he has always been affiliated with Berkshire Hathaway. Nevertheless, for several individuals, we did require additional biographical information to make matches. Fortunately, CEOs of S\&P 500 firms are prominent people, so biographical information is readily available. To find matches for Margaret Whitman, for instance, it was important to know (among other things) that he worked at Stride Rite in Massachusetts prior to joining eBay as CEO in California; in her case, it was also important to check contributions under her nickname, Meg. If a given FEC data entry appeared to match a relevant individual with high likelihood, we included it. Throughout the matching process, we applied a mildly conservative approach, which may have led to under-coding of some matches; this would leave us with data that marginally under-represents some individuals' true giving during all phases of their careers. The implication of using potentially under-representative data on contributions would be a downward bias on averages in our summary statistics and coefficients in our regressions. All in all, we believe that our final dataset very closely reflects the donation patterns made by individuals who served as CEOs of S\&P 500 firms between 1991 and 2008.

${ }^{11}$ All data and code (in E-Views, Stata and R) will be made available on the authors' websites.
} 
individuals in our dataset, or $89.4 \%$, made at least one contribution during the 18 year sample period. $55.9 \%$ of individuals in our sample made a contribution in any given election cycle between 1991 and 2008 - a number far greater than the 10\% of the general population who typically contributes (Ansolabehere, deFigueiredo, and Snyder 2003).

\section{$<$ Insert Table 2>}

The levels and count data on contributions are divided into three categories of individualcycle observations for individuals in different career phases; those who: (i) are the active CEO of an S\&P 500 firms for some fraction of any election cycle; ${ }^{12}$ (ii) are the former CEO of an S\&P 500 firm ${ }^{13}$ or, (iii) will be the CEO of an S\&P 500 firm in the future, but have no such experience leading an S\&P 500 firm prior to that election cycle. This raw data provides initial evidence that the treatment of "becoming a CEO" may impact individuals' political activity.

The mean contribution in any cycle for active CEOs equals $\$ 15,115$, slightly more than the $\$ 13,116$ donated by former CEOs and substantially more than the $\$ 3,075$ given by the preCEO group. All of these values dwarf the mean contribution for the fraction of the general population that makes any contribution, which equals approximately $\$ 115$ (Ansolabehere, deFigueiredo, and Snyder 2003).

The number of target recipients varies for the three career phase groupings as well. Active CEOs and former CEOs give to 4.25 and 3.14 candidates, committees and PACs on average; future CEOs only give to 1.46 counterparties. Individuals in our sample tended to contribute to candidates more frequently than to PACs or party committees.

\footnotetext{
${ }^{12}$ By coding individuals as active CEO if they were only CEO for a fraction of the election cycle, we may be biasing the coefficient estimates in our regressions and averages in our summary statistics downward if the effect of "becoming CEO" truly only applies to individuals while they are in the corner office.

${ }^{13}$ Our definition of "former CEO" includes executive-cycle observations of individuals who have been the CEO of an S\&P 500 firm and may again become an S\&P 500 CEO, but are not for that particular cycle. Only 86 of the 2,198 individuals in our sample are CEOs of S\&P500 firms more than once throughout our sample period.
} 
Regarding the partisan nature of contributions, $72.5 \%$ of individuals donated to both Republican and Democratic candidates, with $37.9 \%$ giving to individuals in both parties within the same election cycle. These facts directly contradict Burris' (2001) claim that CEOs tend to contribute primarily to Republicans, based on data from only the 1980 election cycle.

Figure 2 shows a histogram of all individual-cycle observations broken out by career phases. For all three groups the distribution is right-skewed with the largest mass between $\$ 0$ and $\$ 5,000$; for pre-CEOs, this bucket accounts for over $90 \%$ of the data, while only accounting for approximately $55 \%$ of the data for active CEOs and approximately $70 \%$ for former CEOs. The distribution of contribution levels representing active and former CEOs declines less rapidly than the distribution representing pre-CEOs. It is also interesting to note that there is a small mass of individual-cycle contributions in excess of $\$ 100,000$ — consistent with some individuals giving near (or above) contribution limits.

$<$ Insert Figure 2>

Considering the size of our dataset and the steps involved in its construction, it is remarkably well-behaved. Nevertheless, before moving on to Figure 3, we must address two data anomalies apparent upon inspection of the summary statistics in Table 2. First, negative minimum aggregate contribution levels are observed, when such entries should not occur in practice; they represent only 27 of our 19,782 individual/election-cycle observations. We believe these anomalies reflect refund timing discontinuities-i.e., contributions could have been made in one cycle, but refunds could have been delayed until the next cycle. ${ }^{14}$ Second, maximum aggregate contribution levels exceeding the FEC's legal contribution limits are

\footnotetext{
${ }^{14}$ Contribution refunds occur for a variety of reasons. For example, an individual donor may have exceeded contribution limits to a particular recipient, requiring the recipient of funds to return any dollars over the legal limits once they identify the over-limit contribution. Under normal circumstances refunds should not exceed the initial contributions; however, it is possible they are not processed during the same election-cycle as the contribution.
} 
observed, when such entries should not occur; they represent 677 of our 19,782

individual/election-cycle observations, of which 350 are for active CEOs. Conceivable

explanations for these over-limit entries include: (i) that prior to 2002, FEC contribution limits

did not binding in practice; ${ }^{15}$ (ii) that there may have been timing discontinuities; and, (iii) that the FEC was slow to correct some limit violations. ${ }^{16}$

Figure 3 presents the time series change in contribution levels of individuals in different career phases. Panel A presents the raw data, while Panel B presents restricted data to remove potential bias from anomalous entries. The vertical axis presents the average contribution level for a given election cycle. There is a noticeable upward trend in giving levels. Presidential election cycles are also readily identifiable in Figure 3 as contributions spike in those years, suggesting that timing may affect individuals' giving decisions (Stratmann 1995, 1998). In the 2004 election cycle, a particularly notable peak in giving is apparent for the active CEO group in Panel A; however, it disappears when we look at the same time period in Panel B. ${ }^{17}$ $<$ Insert Figure 3>

\section{Empirical Approach}

In outlining our empirical methodology, we: (i) formally state our testable hypothesis; (ii) clarify our identification strategy; (iii) review our estimation methodologies; and, (iv) discuss

\footnotetext{
${ }^{15}$ Prior to the passage of the McCain-Feingold campaign finance reform in 2002, it was possible for individuals to donate unlimited amounts of "soft money" to parties, but not to candidates, implying that a portion of earlier contribution limits were not binding in practice, and hence aggregate limits were not binding in practice. Moreover, this explanation can explain the majority of anomalous entries - as 301 of the 350 cases of limit violations by active CEOs occurred prior to McCain-Feingold reforms. Nevertheless, after 2002, 49 cases of limit violations by active CEOs (or $0.6 \%$ of relevant observations) could not be explained by non-binding constraints on political giving. ${ }^{16}$ The Progress for America Voter Fund (PFA-VF) PAC is among the most prominent examples of known violators that the FEC was slow to investigate. During the 2004 election cycle, over \$41 million of the \$44.9 million the PAC raised came from individuals who exceeded campaign contribution limit rules. The same PAC also collected more than $\$ 2$ million from individuals who were ineligible to contribute at all under the Federal Campaign Finance Act. After a July 21, 2004 complaint was filed by Democracy 21, the Campaign Legal Center, and the Center for Responsive Politics, the FEC investigated. In 2007, PFA-VF ultimately settled by paying a $\$ 750,000$ civil penalty, but did not admit to any wrongdoing (FEC 2007).

${ }^{17}$ Much of this 2004 spike in Panel A is attributable to a small outlier group of CEOs who, in association with the Progress for America PAC, donated sums in excess of FEC contribution limits and violated campaign finance laws; it took until much later (2007) before the group eventually settled charges against it with the FEC.
} 
how we handle several important data and sampling issues.

\subsection{Main Hypothesis and Average Treatment Effect}

Our main hypothesis, which includes three distinct components, is:

The conditional effect of becoming a CEO of an $S \& P 500$ firm produces no change in the:

i) level of campaign contributions that individual gives;

ii) the number of recipients to whom that individual contributes; and,

iii) the party composition of that individual's contributions.

It is valuable to outline the implied treatment effect being tested. For individual CEOs, we are interested in the influence that being the leader of an organization (i.e., becoming or leaving the CEO role, respectively) has on political behavior. Stated more formally, the average effect of being a CEO on an individual's political activities, $\tau$, can be written as:

$$
\tau=\mathbf{E}\left[Y_{i t} \mid \alpha_{i}, \gamma_{t}, X_{i t}, C E O_{i t}=1\right]-\mathbf{E}\left[Y_{i t} \mid \alpha_{i}, \gamma_{t}, X_{i t}, C E O_{i t}=0\right]
$$

where $Y_{i t}$, the dependent variable, has three configurations that correspond to the three parts of the hypothesis: (i) the total dollar-value of campaign contributions; (ii) dispersion, or count, of targeted candidates, party committees and PACs; and, (iii) the partisan composition of contributions - i.e., the ratio of giving to Republicans divided by the sum of contributions to both Republicans and Democrats.

$\alpha_{i}$ represents fixed and unobserved individual-specific effects (i.e. observation unit fixed effects); they include characteristics such as individuals' long-standing ideologies, private interests in politics, education levels, ethnicities, genders, etc. (Joulfaian and Marlow 1991). Election cycle fixed effects covering each two-year period (i.e., time fixed effects) are denoted by $\gamma_{t}$; these capture the trends exhibited in Figure 3 and control for changes in legal contribution limits shown in Table 1.

$X_{i t}$ is a vector of observable and time-varying control variables. The controls in which we 
are most interested are those that may drive political contributions but that are not perfectly correlated with changes in career status. The most obvious, especially in light of the consumption hypothesis for giving, is the level of CEOs' compensation, a factor that represents individuals' capacity to make contributions. Our preferred models are parsimonious and focus on the CEO treatment effect alone. Nevertheless, several robustness checks incorporate control variables to account for alternative hypotheses.

\subsection{Statistical Identification and Underlying Assumptions}

Formally, we are testing whether $\tau=0$ — that is whether the treatment, becoming an S\&P $500 \mathrm{CEO}$, has any effect on individuals' campaign contributions. Finding a nonzero value for $\tau$ implies: (i) that our statistical hypothesis must be rejected, (ii) that the treatment causes a change in individuals' behavior, and (iii) that individuals' leadership roles within organizations stimulate personal political contributions.

Statistical identification is derived from changes in individuals' CEO status over their careers. Hence, we exploit variation in the time series change of individual behavior from before, during, and after individuals' tenures as CEO of S\&P 500 firms. These within observation-unit differences allow us to examine the implications of "being a CEO" against the counterfactual trend. This over-career variation is an overlooked source of identification useful for studying factors that influence individuals' political behavior. Changes in political giving associated with individuals' roles at organizations permit inference on the determinants of personal campaign contributions under certain underlying identification assumptions.

The treatment effect in our estimation is captured by dummy variables that indicate individuals' career statuses vis-à-vis the CEO role of S\&P 500 companies. The treatment is 
disaggregated into two components: one for active CEOs and another for former CEOs. ${ }^{18}$ These treatment groups are contrasted with pre-CEOs - individuals who have not yet had the experience of leading an S\&P 500 firm.

The treatment of "being a CEO" is believed to be conditionally exogenous. Among the pool of senior executives who could be selected, becoming an S\&P 500 CEO is extremely competitive. There is significant randomness across two dimensions, both of which support the exogeneity of the treatment. First, most firms' selection procedures do not anoint clear successors, so the average senior executive does not have ex ante knowledge that he is going to receive the CEO treatment. Second, even if clear succession plans do exist, the timing of the treatment is unknown and CEO succession normally takes less than an election cycle.

Combining both selection and timing considerations leads us to believe that the treatment is plausibly exogenous; however, we do test the validity of this assumption in a falsification test examining the treatment of externally hired CEOs. ${ }^{19}$

Measuring the influence of the treatment effect in (1) also requires the assumption that “being a CEO” alters neither one's conditional opportunity for political involvement nor one's political preferences. These assumptions are broadly plausible. There is no legal restriction limiting which U.S. citizens can make campaign contributions. Moreover, it is unlikely that individuals' political preferences and ideology experience large fluctuations over their lifetimes; it is even less likely in the shorter period in which they become S\&P 500 CEOs - this is especially true considering that most were lower-level executives prior to being selected.

Finally, it is exceedingly unlikely that S\&P 500 CEOs are recruited primarily based on

\footnotetext{
${ }^{18}$ Active CEOs are individuals that hold the title during a given election cycle. Former CEOs are individuals who are not chief executives for a given cycle, but have occupied that role previously. Former CEOs are no longer the face of their firms, but often remain involved via directorships, stock ownership and advisory duties.

${ }^{19}$ Within any firm, it may be possible for a particular individual to have ex ante knowledge that he will receive the treatment and become a CEO internally, but similar ex ante knowledge is extremely unlikely for external hires.
} 
their prior political contributions. Boards making appointment decisions are concerned foremost with executives' business acumen, (Kaplan, Klebanov, and Sorenson 2012) not individuals' historical campaign contributions. Nevertheless, we examine this hypothesis with a falsification test.

\subsection{Estimation Methodologies}

Two estimation approaches are used: (i) panel data methods which control for unobserved, but fixed, omitted variables and (ii) count data models, enabling examination of the component of our main hypothesis dealing with the number of political giving targets.

All panel models use a within estimator and include individual and election cycle fixed effects. Even though our dependent variables are truncated, we opt not to use Tobit models for three reasons. First, since our main treatment is a dummy variable, the conditional expectation function of a Tobit model is identical to a linear specification (Angrist and Pischke 2010). Second, linear panel models generate more accessible results, since interpretation of coefficients in Tobit models is not straightforward. Third, Tobit requires stricter underlying assumptions.

Count data models are used to examine the dispersion of contributions where the dependent variable takes non-negative integer values as in the second component of our hypothesis. We specify panel data negative binomial models including both individual and time fixed effects (Cameron and Trivedi 1998). Table 2 indicates that the dependent, count variable is over-dispersed, justifying negative binomial distributions throughout.

\subsection{Sample Selection and Data Anomalies}

There are two issues related to the data we use in our analysis that are important for the robustness of our results: (i) whether or not we include pre-treated individuals in our sample; and (ii) how we deal with the anomalous entries in our raw data. 
Our complete dataset contains 2,198 individuals and 19,782 observations; however, some individuals entered the dataset as CEO. In effect, these individuals were pre-treated as we do not have any information on their pre-CEO behavior. Including these individuals in our analysis may pose a problem for identification of our primary parameter of interest; we want to compare like to like. Excluding pre-treated individuals yields a restricted sample of only 14,004 observations. Hence, we face the trade-off of (a) having a larger number of observations by including all CEOs, or (b) ensuring we are testing for changes in political behavior associated with obtaining an S\&P 500 CEO title by restricting our sample to include only those individuals for whom we observe pre-CEO political activity. In the majority of our results tables, we present estimates for the more restrictive approach, since we are primarily interested in changes in behavior resulting from obtaining new leadership roles. Nevertheless, we ran all tests on both restricted and unrestricted samples. ${ }^{20}$

We also remain agnostic towards whether or not using the raw data, including some anomalous entries, yields valid results. In a first pass, we analyze the raw data. We then re-run our entire analysis using a restricted or winsorized dataset to ensure our findings are robust to the anomalous entries described in section two. ${ }^{21}$ We find no substantive differences in any of our econometric models; likewise, we find no substantive difference when we exclude anomalous entries altogether. For brevity, after Table 3, we display results using only the winsorized data whenever the dependent variable is the aggregate amount contributed as this data best reflects the average behavior of CEOs had all individuals adhered to legal limits. ${ }^{22}$

\footnotetext{
${ }^{20}$ The magnitude and sign of the CEO effect is robust to the inclusion in the sample of pre-treated individuals. Parameters for most models have similar statistical significance as well. Estimates are available from the authors. ${ }^{21}$ We constructed a restricted data series that effectively winsorizes the data by setting negative aggregate contribution entries for individual/cycle-year observations to zero and restricting maximum entries to aggregate election cycle limits (unless the excess dollars contributed were made using "soft money").

${ }^{22}$ Results not displayed using the un-winsorized data are available from the authors.
} 


\section{Results}

This research focuses on whether becoming the leader of an organization causes a sharp change in political behavior. We examine the personal political contributions of S\&P 500 CEOs before, during and after their tenure as chief executive. We specify a hypothesis that contains three parts. It states that being a CEO should have no effect on the level, count, or partisan composition of individuals' campaign contributions. A rejection of the first two parts of this hypothesis provides evidence that individuals' political behavior is driven by their roles within organizations. Robustness checks and falsification tests support our claims.

\subsection{Main Findings}

Our main results demonstrate that becoming the CEO of an S\&P 500 firm does produce a statistically and economically significant increase in the amount of money individuals contribute to election campaigns as well as an increase in the number of recipients of those funds. The effect on the partisan composition is negligible. In other words, we reject our main hypothesis for donation levels and counts, which implies that becoming the leader of an organization does cause a distinct change in conduct. Weak evidence on the share of contributions aimed at Republicans makes it difficult for us to draw compelling inferences with respect to changes in party allegiances.

Overall, we conclude that these results represent a true causal effect and that it is unlikely that individuals would have so dramatically altered their political giving if they had not become leaders of their organizations. Increases in both the amount of money that individuals give and in the number of political targets receiving contributions implies that being an active CEO causes individuals to engage in additional political giving relative to other phases or their careers.

\subsubsection{Amounts}

Table 3 examines the effect of being a CEO on the size of individual campaign 
contributions in dollars. The dependent variable in columns I through $\mathrm{V}$ is total individual campaign contributions subject to the sample restriction and dependent variable transformations discussed in sub-section 3.4. Money flowing to political candidates, PACs and political parties are shown in columns VI, VII and VIII, respectively. All models include both individual and time fixed effects. The main conclusion from Table 3 is that relative to other phases of an individual's career being an active CEO produces a statistically and economically meaningful increase in the dollar value of political contributions and that this effect holds across types of giving. Taking a leadership role within an organization influences personal political behavior.

These results imply that we must reject part (i) of our main hypothesis for campaign contributions aggregated across all political counterparties and when disaggregated at the level of candidates, PACs and party committees. Our preferred model is in column V. This specification restricts the sample by excluding individuals who were CEOs at the onset of the period of analysis (i.e., we do not observe any pre-leadership information) and recodes over-limit and negative contributions to the cycle maximum and zero respectively. Model $\mathrm{V}$ demonstrates that being an active CEO causes a $\$ 4,029$ increase in the per cycle political campaign contributions. This is a $130 \%$ increase from the pre-CEO level of $\$ 3,075$.

If we do not confine the dependent variable to the legal campaign limits but still exclude those who enter as CEO, column IV shows that being the leader of an organization produces a $\$ 5,759$ increase in per cycle political contributions. Column I includes all individuals, even pretreated individuals, and does not recode the dependent variable, allowing contributions to be negative and exceed legal limits. Although statistical significance is less clear, becoming a CEO still leads to an economically meaningful $\$ 3,700$ increase in per cycle contributions. Using different sample restrictions such as dropping all negative and over-limit contributions, columns 
II and III display similar results with estimates corresponding to $\$ 2,452$ and $\$ 3,776$. Altogether, these models corroborate the core result that becoming the leader of an S\&P 500 firm causes a distinct change in an individual's political behavior.

We find a similar pattern when we look at the contributions directed towards candidates, PACs and parties. Being the head of an S\&P 500 firm causes individuals to give more to each group. All three models show that the CEO treatment effect is sizeable and statistically significant. Relative to their pre-CEO career, individuals give $\$ 885$ more to political candidates and an additional $\$ 1,137$ to PACs. Contributions to party committees see the largest increase with leaders increasing their donations by an extra $\$ 1,839$.

Considering the per candidate and per PAC contribution limits (Table 1), these results suggest that it is likely that becoming the leader of an organization also triggers individuals to diversify their giving to a greater number of candidate, PAC and party targets. This is further examined using count models in Table 5.

While the CEO treatment effect in Table 3 is strong, a similar claim cannot be made for former CEOs. Model specification has a strong influence on this group. Estimates range from negative values to sizable positive effects and it is rare for the former CEO coefficient to be statistically significant. The only notable result is that former CEOs give $\$ 500$ and $\$ 1000$ less to candidates and PACs. This research focuses on the implications of becoming the leader of an organization on political behavior. It is less interested in the activities of former CEOs. Nevertheless, that we cannot reject the hypothesis of a difference between pre- and post-CEO campaign contributions implies that it truly is the $\mathrm{CEO}$ or leadership designation which causes a change in behavior. We can interpret this as implying the political activities of an active S\&P 500 CEO may not align completely with their private preferences. Perfect alignment would 
imply that there is no observable change in conditional contribution levels.

<Insert Table 3 Here>

To determine whether the effect we observe is driven by increased contributions on the intensive or extensive margin, we run regressions on sub-samples where individuals are categorized according to their campaign contributions prior to becoming an S\&P 500 CEO. Table 4 demonstrates that an economically meaningful and statistically significant CEO effect persists along both the intensive and extensive margins; however, the majority of the overall effect in Table 3 is driven by giving on the intensive margin-i.e. by increased contributions from individuals who gave prior to becoming CEO rather than by individuals who chose to contribute only once they became CEO.

Of the 1,556 individuals in our restricted sample (i.e., those who did not enter the dataset as an S\&P 500 CEO), 1,096 individuals made some form of contribution prior to becoming an S\&P 500 CEO. The remaining 460 individuals, prior to becoming CEO, did not give any money to political campaigns. Within this sub-sample of 460 individuals, $258(56 \%)$ initiated giving after becoming CEO. Consequently, we re-run our core regression on three sub-samples divided into group of: (i) all individuals who gave prior to becoming $\mathrm{CEO}$ - i.e. intensive margin contributors; (ii) only the individuals who did not give prior to becoming CEO but did contribute after they obtained the leadership title-i.e. extensive margin contributors; and, (iii) all individuals who did not give prior to becoming $\mathrm{CEO}$ - i.e. the entire extensive margin which includes both extensive margin contributors and extensive margin non-contributors.

Column I of Table 4 limits the sample to intensive margin contributors and illustrates that the leadership effect remains positive and significant. The magnitude of the point estimate equals $\$ 4,950$ - and is about $\$ 1000$ or $25 \%$ larger than when include all individuals in our 
sample (i.e. when comparing to Table 3, Column V). This suggests that the effect on the intensive margin is greater than the average treatment effect. Column II considers extensive margin contributors and demonstrates that, for individuals who decided to give only once they became CEO, their average donations while in office were $\$ 3,158$ compared to the zero dollars they contributed during the period before they became chief executive. Finally, Column III considers the full extensive margin and still reveals an economically meaningful and statistically significant leadership effect. Indeed, the magnitude of the coefficient on the extensive margin is approximately half of the average treatment effect identified in Table 3. Taken together these three models suggest that becoming the $\mathrm{CEO}$ of an $\mathrm{S} \& \mathrm{P} 500$ firm causes individuals to increase their campaign contributions and that leadership roles induce donations on both the extensive and the intensive margins - although the effect appears smaller on the extensive margin.

\section{<Insert Table 4 Here>}

\subsubsection{Counts}

Table 5 contains results for the count data models. All models exclude individuals who entered as CEO, focusing on individuals who received the CEO treatment during our sample period. The dependent variable is unique targets, be they candidates, PACs or party committees. If an individual contributed to the same target on multiple occasions within an election cycleby, for example, giving to the same PAC quarterly throughout the election cycle - this only counts as a donation to a single unique political counter-party.

Columns I through IV demonstrate a statistically significant increase in the number of contributions from individuals once they become CEO. Overall, CEOs give to 0.34 additional targets relative to their pre-CEO state. A similar pattern holds for contributions to each: candidates, PACs, and party committees. Being the leader of an S\&P 500 firm leads individuals to give to 0.29 more candidates, 0.40 additional PACs, and 0.35 more party committees. Based 
on these results we must reject part (ii) of our hypothesis. Being the leader of an organization causes individuals to give to more targets.

Following the results of Tables 3 and 4, it is not surprising that CEOs increase the diversity of their giving. The combination of more money and campaign contribution limits foreshadowed this result. Still, that the number of candidate, PAC and party committee recipients increases in a roughly proportional fashion is notable. Active CEOs do not concentrate on one type of political contribution at the expense of the alternative categories. Further, unlike in Table 3, the results for the former CEO regressor illustrate a distinct pattern. Once an individual stops being CEO he is more selective in his giving than prior to holding the leadership role. He contributes to fewer candidates, PACs, and party committees than he did before; among these political counterparties, the influence of being a former CEO is smallest and least statistically significant for contributions to political parties.

$<$ Insert Table 5 Here>

\subsubsection{Partisanship}

While we reject our main hypothesis for amount contributed and count components, we cannot draw strong conclusions regarding the partisan composition of political donations. Table 6 presents the results from the composition models. ${ }^{23}$ This table concentrates on the conditional change in fraction of dollars that are given to Republican candidates and party committees by individuals who opted to give to these targets. We do not consider PAC contributions here. ${ }^{24}$

\footnotetext{
${ }^{23}$ The number of observations in these regressions drops because we can only make inferences about the change in the partisan orientation of individuals that become leaders if they have a record of giving prior to assuming leadership roles because it is impossible to know what their partisan orientation would have been if they did not give before. Hence, we can only make predictions about the intensive margin of changes in partisan giving.

${ }^{24}$ PAC contributions are not considered for two reasons. First, deciding how to label PACs as Republican or Democratic is not an obvious process in many cases as PACs give to candidates/committees of both parties. Hence, it would require some assessment of the flow-through of dollars to party-affiliated candidates and committees. Second, by donating to a PAC, an individual effectively transfers their political campaign contribution decision to another agent. An individual may agree with a PAC's general objectives, but they forego their decision-rights on
} 
Table 6 demonstrates that being an active CEO generates an increase of between $3.0 \%$ and $4.9 \%$ of contributions flowing to the Democratic Party along the intensive margin. At a 5 percent level, this result is statistically different from zero only in columns I and III. Coefficients for the fraction of donations made to Republican candidates in columns IV through VI are not statistically different from zero. More importantly, the effect is less than $1 \%$ in magnitude which would entail a tiny change in money directed at a given party. On the whole, these results make it difficult to infer any conclusion on changes in giving to Republicans and Democrats due to contributors' leadership status. Likewise, the results for the former CEO variable follow a similar pattern. Given that partisanship does not appear to change for individuals who gave prior to becoming CEO, we are not able to reject part (iii) of our hypothesis. Partisan leaning is not strongly swayed by assuming leadership positions. This result is consistent with long-standing ideology and preferences remaining constant and being distinct from an individual's role in an organization.

\section{<Insert Table 6 Here>}

\subsection{Robustness Checks}

In the above tables, identification is clear provided the treatment is unexpected insofar as individuals do not know ex ante that they will become CEO of a particular firm or at least not when. This assumption is plausible at S\&P 500 firms. Nevertheless, several robustness and falsification tests buttress our conclusions. Individual and election-cycle fixed effects capture characteristics such as long-standing personal preferences and differences between elections, yet time-varying covariates such as individuals' salary and firm-linked wealth also influence peoples' ability and motivation to make campaign contributions; we examine these and other control 
variables next. We also run falsification tests to ensure identifying assumptions hold.

\subsubsection{Specifications including Controls for Alternative Hypotheses}

While our preferred models are the parsimonious ones above, we consider alternative factors that may drive our results. Table 7 re-examines our models of the aggregate amount contributed, from Table 3, by including potential omitted variables on (i) salary, (ii) ownership stakes, and (iii) giving to ideological PACs. Our main result remains robust across specifications, since being an active CEO still generates an economically meaningful and statistically significant increase in the amount that an individual contributes to political campaigns. These additional factors dampen the CEO treatment effect little if at all.

ExecuComp contains information on CEO salary and the number of the firm's shares owned for the vast majority of individuals while they are active CEOs. Entries for these data series are sparser for individuals in pre- and post- CEO career phases; ${ }^{25}$ hence, we use various imputation rules to fill missing entries. ${ }^{26}$ Taken together, regressions using actual and imputed salary data in Columns I, II, and III enable us to infer estimates for the leadership effect that bracket its true value and enable us to test the robustness of our main result to extreme assumptions. $^{27}$ Based on these results we can confidently claim that after accounting for an individual's time-varying salary the active CEO point estimate is economically meaningful,

\footnotetext{
${ }_{25}^{25}$ For these observations when individuals are in pre- or post- CEO career phases only roughly 1,000 are complete.

${ }^{26}$ The first imputation rule involves replacing all missing salary entries with zero, which is the lower bound on possible value, but a clear underestimate of individuals' true income. For the remaining two imputations, we replace missing salary entries with the minimum and maximum salary observed for each individual in the dataset. Filling with the minimum observed salary for each individual is likely the closest representation of an individual's smoothed career income. Filling with the maximum observed salary for each individual is likely to overstate individuals' income in the periods where entries are missing and is likely the upper bound over individuals' careers. 27 The model, presented in column I, overstates to the greatest extent possible the influence of income on political campaign contributions; growth in salary due to becoming the CEO is greater than the true change in this regression, so more variation in the dependent variable is attributed to this factor than in reality. Even considering the overstatement of the effect of salary on campaign contributions, being an active CEO of an S\&P 500 firm causes individuals to give nearly $\$ 2000$ more to political campaigns than in other phases of their careers. In Column II, where salary is replaced with the minimum observed for an individual, the point estimate on the CEO variable equals $\$ 2,509$. In Column III, replacing absent salary information with an individual's maximum observed value understates the influence of a change compensation level to the utmost extent; results from such a regression appear in column III where the CEO effect on giving equals $\$ 3,761$.
} 
statistically significant and lies in an interval between $\$ 1,965$ and $\$ 3,761$.

The models in columns I, II and III provide evidence related to the perspective that campaign contributions are a form of consumption (Ansolabehere, deFigueiredo, and Snyder 2003). They show the amount given increases with salaries. Political contributions have the properties of a normal good, since the people spend 0.2 to 0.5 cents more on them for each additional dollar they earn. Notwithstanding support for the consumption perspective, the large leadership effect we identified earlier persists suggesting that individuals are influenced not only by consumption motives, but also by leadership roles they play within organizations.

In addition to the consumption perspective, campaign contributions are frequently viewed as strategic investments in political capital (e.g., Kroszner and Stratmann 1998). Gordon, Hafer and Landa (2007) devise a test of strategic motivations as drivers of campaign contributions at the individual level; they show that when executives have a greater fraction of their wealth linked to their firm, they make greater campaign contributions. To account for their finding, we include the fraction of shares in a firm an executive owns as an additional control variable in columns IV and V of Table $7 .^{28}$ The results confirm the predicted positive relationship between ownership stakes in the firm and campaign contributions. In column IV, a $1 \%$ increase in ownership leads to an additional \$195 donated to political campaigns. More importantly, for this research, the $\mathrm{CEO}$ variable remains statistically significant and within the range of previous estimates. Column V further confirms the leadership effect by including both salary and percentage of shares owned.

As a final robustness check, we include a dummy variable that indicates whether an

\footnotetext{
${ }^{28}$ As with the salary data, entries on ownership are complete for the majority of individuals while they are active CEOs but not during other career phases. As with the salary data, we fill missing entries on ownership with zero and attribute more variation to this variable than likely exists. Hence, we increase the likelihood that we underestimate the CEO treatment effect.
} 
individual contributed to an ideological PAC. ${ }^{29}$ Intuition suggests that strategically-motivated CEOs who give to PACs should focus on business-linked PACs; however, some may contribute to ideological PACs if they have persistent, personal political preferences. Consistent with that intuition, Column VI of Table 7 shows that individuals who gave to ideological PACs gave over $\$ 10,000$ more than those who did not. Nevertheless, the leadership effect remains robust and its magnitude hardly changes: being an active CEO still leads to additional giving of $\$ 3,611$ after controlling for whether or not individuals gave to ideological PACs.

$<$ Insert Table 7 Here>

\subsubsection{Falsification Tests}

Table 8 includes three falsification tests. First, we examine whether an individual was promoted internally or became CEO via an external search process. Next, a set of placebo models test that the leadership effect occurs upon appointment to CEO and not before. Finally, we reverse dependent and causal variables to test whether lagged contributions are able to predict future CEO status. In all cases, our identification strategy and main results are robust, adding credibility to the conclusion that individuals alter their political giving behavior once they take a leadership role within an organization.

External recruitment of CEOs is substantially less common than internal promotion (Chan 1996). Endogeneity of the treatment is possible if internal candidates are able to predict that they are destined to become leaders of their firm. Becoming the CEO of an S\&P 500 firm is extremely competitive, so an individual's ability to anticipate his promotion internally should be limited. It is even less likely that external CEOs have ex ante knowledge that they will take the helm of a firm for whom they are not currently employed. Hence, additional support for our

\footnotetext{
${ }^{29}$ The coding comes from the Center for Responsive politics classification of PACs as business, labor, or ideological.
} 
main results could come from examining CEOs that were recruited externally. If the main result holds for external as well as internal CEOs, any lingering CEO treatment endogeneity concerns should be assuaged. Columns I, II and III in Table 8 present specifications that include distinct internal and external CEO variables. In each case, the external CEO variable is economically meaningful and statistically significant and the internal CEO variable remains so as well. Although external CEOs appear to donate slightly more money to political campaigns, we are unable to reject the hypothesis that internal and external CEOs donate the same amount. Consequently, we are confident of the exogeneity of the treatment for both internally and externally recruited executives and our main result holds: becoming the leader of an organization causes individuals to contribute to political campaigns at a rate that is greater than can attributed to underlying personal preferences alone.

Next, the placebo models, as illustrated in columns IV and V, provide additional assurance that the leadership effect occurs only when individuals move into leadership roles. Lagged contributions are used as the dependent variable and a disaggregated CEO variable where an individual's first cycle enters as a distinct covariate. If the relationship between contributions and organizational leadership is truly causal, then lagged contributions regressed on a false CEO signal should produce an estimate that is either statistically insignificant or has the wrong sign. This is what we find. In both columns IV and V, there is a negative coefficient on the time shifted dependent variable and false first period treatment effect, a result that bolsters our identifying assumptions. Untreated individuals do not alter their contribution behavior.

Finally, column VI demonstrates that lagged contributions are a poor predictor of CEO status, further strengthening the exogeneity of the CEO dummy variable. Based on the robustness checks and falsification tests, we are assured that taking a leadership role within an 
organization leads individuals to alter their political behavior.

<Insert Table 8 Here>

\section{Discussion}

Given the dearth of research on individuals' personal political campaign contributions, especially when compared with corporate-linked contributions, the effects we identify are unique. We rigorously test whether playing a leadership role in an organization causes individuals to alter their personal political giving patterns. We confirm that there is an abrupt change in personal political contribution patterns when an individual takes the helm of an S\&P 500 firm.

While this finding is inherently interesting, it is also surprising that no current theory overtly predicts this leadership effect. This fact makes it important to discuss potential explanations for and implications of this result (i) in light of the existing literature on corporate-linked campaign contributions, and (ii) allowing for possible alternative mechanisms at the individual rather than corporate level.

\subsection{Interpreting our Results vis-à-vis Existing Perspectives}

Two of the three prominent hypotheses explaining campaign contributions focus on corporate-linked PACs' contributions rather than individuals' contributions; those perspectives suggest that corporate-linked political giving (i) represents an agency problem within the firm, or (ii) serves as an instrument through which politics supports corporate strategy. A third hypothesis, one which has not been subject to the same level of scrutiny, is that campaign contributions reflect (iii) a form of consumption or political participation. To date, the literature has presumed that these three hypotheses are mutually exclusive. By focusing on individuallevel campaign contributions, we begin to disentangle these competing ideas - and illustrate how at least two and perhaps all three motivations for giving may co-exist. 
Results from Table 7 support the notion that some fraction of campaign contributions are made by individuals as a form of consumption. Campaign contributions are consistent with the properties of a normal good in that when individuals' incomes increase so does the amount allocated to political giving. The consumption argument appears to explain why many individuals donate before, during, and after their tenure as leaders of organizations. Nevertheless, the consumption story cannot explain all of individuals' political giving behavior; in particular, the consumption story fails to explain why individuals deviate from their long-standing contribution patterns once they become the leader of an organization. Room remains for variants of the agency or strategy hypotheses to explain some portion of base-level contributions as well as the bump in giving we see when individuals become leaders of organizations.

Consistent with the strategy perspective, the amount of giving that cannot be explained by the consumption perspective alone could be an attempt by leaders to influence policy in order to benefit their organization through personal rather than corporate means. This motivation could be supported by the reality that donations increase with the fraction of shares individuals own in firms they lead. Nevertheless, we cannot rule out that the bump in personal giving upon assuming leadership roles may also be consistent with an agency perspective if politics become a distraction for organizations' leaders. Variants of any two or even all three of these existing hypotheses could provide partial explanations for the patterns we observe in individual giving.

\subsection{Individual-Level Mechanisms that Could Explain Leaders' Additional Giving}

Our results call for new, nuanced hypotheses to explain what factors related to serving in leadership roles at organizations could explain individuals' motivations to give different amounts to political campaigns during distinct career phases. Hypotheses such as agency and strategy, formulated to explain corporate-linked PACs' contributions, can only explain individuals' 
contribution patterns with reworking. The mechanisms offered below could explain the result that individuals give more money to more political counterparties once they assume leadership roles in organizations, while maintaining their partisan orientation. Any combination of these hypotheses could explain the leadership effect we identify, as they do not have to be mutually exclusive.

\subsubsection{Contributions Opens Doors for Individuals}

Individuals in leadership roles may need to "open doors" (Austen-Smith 1995, 1998) to access politicians on a personal basis to achieve goals that are important for their organization. While this argument is similar to the strategy hypothesis linked to corporate PACs, and may work in tandem, it differs because it provides an explicit explanation for why leaders make personal contributions by recognizing that political transactions occur on an individual rather than corporate basis. Individuals may want politicians to know them personally because it eases any subsequent political requests leaders may make on behalf of their organization. When individuals are not in leadership roles, personal relationships with politicians are likely less important to their employment duties as they are less likely to make political requests. Moreover, for a leader to attend a political fundraiser on behalf of his organization, he must make a personal campaign contribution, identifying himself with both his title and employer.

\subsubsection{Contributions are Part of the Job}

The core activities of a leader include not only overseeing organizational strategy, finances, and liaising with oversight boards, but also serving quite literally as the public face of the organization (Guthey and Jackson 2005). Political involvement, whether instrumental for the organization or not, may simply be another part of the job - one of the ways leaders are expected to participate in the larger community. In this way, leaders' political giving may be like their giving to charities (Ansolabehere, deFigueiredo, and Snyder 2003; Andreoni 2006). 
Similarly, personal giving by leaders may supplement contributions from linked PACs. In order to maintain goodwill with both stakeholders and political groups, government relations officers may push organizations' leaders to contribute to particular candidates, parties, and PACs. Even though leaders have formal authority over their private finances, they may listen because government relations officers have real authority over corporate political strategy (Aghion and Tirole 1997). For example, government relations officers may request that leaders attend certain political fundraisers, requiring them to write a personal check.

\subsubsection{Contributions set Organizational Culture}

Personal political contributions by leaders may help set or strengthen organizational cultures. Leaders set social norms and expectations for members of their organization—and as such may shape their members' personal behavior (Akerlof 1980; Cremer 1986; Bernheim 1997; Benabou and Tirole 2006; Bandiera, Barankay, and Rasul 2010). The more members of an organization that give to its linked PAC, the more effective its government relations office could be; if members also mimic their leaders' personal political giving beyond contributing to a linked PAC, it could amplify potential benefits accruing to the organization. Leaders' personal political behavior, may also fortify internal culture. For example, an organization's members may be more motivated to perform for leaders who demonstrate a personal, visible commitment to endeavors they believe will eventually benefit them personally or society more broadly.

\subsubsection{Contributions are Reflective of Repressed Political Desires}

Another reason individuals may give more once they become leaders is that they previously repressed their personal desires to give to political campaigns for fear of the consequences in the workplace. If an individual is not the leader of an organization but wants the current leader to view him favorably, he may choose not to make campaign contributions if his own political preferences differ from the leader's. Hence, once and individual becomes the 
leader of an organization, monitoring from the previous leader is no longer a threat, allowing that individual to act freely on previously repressed desires (Gibbons and Murphy 1992; Prendergast 1993). Moreover, even if an individual had political preferences aligned with the current leader of his organization, he may withhold giving for fear that any potential future leader, other than himself, may have different preferences.

\subsubsection{Contributions are the Result of Post-Organizational Ambitions}

Personal political contributions by high status individuals could also be related to their ambitions beyond their current organizations (Fama 1980). Once individuals become leaders, they may abruptly change their political giving because it becomes clear to them that the next step in their career step cannot be within their current organization. Those in leadership positions outside of government may make campaign contributions upon entering high profile positions because they want to secure high profile political jobs as their next career step. ${ }^{30}$

Related to post-organizational ambitions, those in leadership roles may attend political fundraisers to improve their own standing among colleagues in hopes of winning board seats or securing higher profile leadership positions outside of government (Fracassi and Tate 2012). Unlike some of the other individual-level mechanisms, it is more difficult to link leaders' postorganizational ambitions to their organizations' objectives. While this mechanism is focused on individual rather than linked PAC contributions, this motivation for personal giving may be consistent with an agency problem if it becomes distracting for leaders.

\subsubsection{Contributions are the Result of being Targeted by Politicians}

Individual political donations could be driven by the demand side of the market for campaign contributions. Individuals' may become targets for solicitations from politicians if

\footnotetext{
${ }^{30}$ As recent examples, Donna Shalala transitioned to the role of the Secretary of Health and Human Services under Bill Clinton after her tenure as Chair of the Children's Defense Fund non-profit and Hank Paulson transitioned to the role of U.S. Treasury Secretary under George W. Bush after his tenure as CEO of Goldman Sachs.
} 
their leadership status signals their potential and willingness to give. New pleas for help and personal solicitations may explain the effect we observe, since they induce donations on both the intensive and extensive margins in other contexts, such as alumni giving to universities (Meer 2011; Meer and Rosen 2011).

Politicians may be interested in finding certain individuals who can serve as the lowest cost providers of campaign finance (Francia et al. 2003) — and leaders of high profile organizations may be a logical place to start. Once individuals become leaders, they have known contact information, compensation, and interests in specific political outcomes. Before these individuals became leaders, much of this information was opaque. Even if individuals gave to particular politicians or parties before ascending to leadership roles, self-interested politicians may now ask for larger contributions. Hence, politicians can extract rents from organizations' leaders whether or not the politicians intend to deliver policy benefits. Individuals in leadership roles may not have a choice but to give if politicians can effectively hold them up using threats such as delaying policy action or supporting potentially adverse legislation.

A unique implication of this potential explanation of the effects we observe is that all of the benefits from leaders' increased political contributions accrue to politicians — and not to the individuals making the contributions or their organizations as typically suspected.

\section{Conclusion}

By focusing on individuals' campaign contributions over their careers, this research addressed a gap in the campaign contributions literature. We demonstrated that when individuals become the leader of their organization, their political behavior exhibits a sharp change relative to other phases in their career. Specifically, we show that becoming the CEO of an S\&P 500 firm causes individuals to (i) donate approximately $\$ 4,000$ more to political campaigns and (ii) 
give to more unique recipients, but (iii) does not appear to change partisan allegiances. These statistical results are robust to the numerous specifications including a variety of control variables - and identification is reinforced through several falsification tests.

This paper provides an initial foray into a new research agenda — one that concentrates on individuals' campaign contributions. Here we focused on identifying the effect of becoming a leader of an organization on individuals' personal campaign contributions. The time cost and difficulty of assembling coherent and reliable data in this area may explain why prior research has not focused more on individual giving despite its importance. As should be clear from this research, any analysis of campaign contributions that overlooks individuals and their motivations for giving can only provide answers about part of the total story.

While we tested for internal validity, we do not know about the external validity of our findings. The effect may or may not hold in a dataset that (i) includes leaders of firms smaller than those in the S\&P 500 or (ii) focuses on contributions to local politicians rather than federal ones. Moreover, while we introduced this research with illustrative examples of a potential leadership effect on personal campaign contributions of individuals at non-profit organizations and labor unions as well as firms, we chose to limit the scope of our analysis to business leaders to improve the reliability of our statistical results. Future research could potentially address each of these limitations to external validity if it addressed challenges we noted; confirming the existence of the effect for non-profit organizations and labor unions would be most valuable.

Going forward, it may also be valuable to test some of the potential mechanisms we proposed to explain why the additional political giving of individuals that we identified occurs once they assume leadership positions at organizations. Identifying this distinct leadership effect alone is a contribution to the literature on campaign finance. Nevertheless, our understanding of 
the effect could be enhanced by finding evidence that supports one or more underlying mechanisms, including new ideas such as (i) that political giving increases in leadership roles as a result of previously repressed preferences, (ii) that the increase in campaign contributions is driven by the propinquity of leader's post-organizational plans, or (iii) that the bump in political giving is a function of politicians on the demand side of the market soliciting campaign finance from easy targets. Currently, there is little guidance as to which if any of these mechanisms provides the best description of leaders' political behavior.

Finally, our new dataset may be useful in other studies. For example, private political contributions may act as an instrument for other areas of corporate strategy — an idea consistent with Hillman, Keim, and Schuler's (2004) notion that giving by leaders is an antecedent to corporate political activity more broadly. 


\section{References}

Aggarwal, R.K., F. Meschke and T.Y. Wang, 2011. "Corporate Political Donations: Investment or Agency?" 2008 WFA Meeting Paper; American Finance Association 2012 Chicago Meetings Paper. Available at SSRN: http://ssrn.com/abstract=972670.

Aghion, P., and J. Tirole. 1997. "Formal and Real Authority in Organizations." Journal of Political Economy. 105(1): 1-29.

Andreoni, J. 2006. "Leadership Giving in Charitable Fund-Raising." Journal of Public Economic Theory. 8(1): 1-22.

Angrist, J.D. and J.S. Pischke. 2009. Mostly Harmless Econometrics: An Empiricists Companion. Princeton University Press: Princeton.

Ansolabehere, S., E. Snowberg, and J. M. Snyder. 2005. "Unrepresentative Information: The Case of Newspaper Reporting on Campaign Finance." Public Opinion Quarterly. 69(2):213-231.

Ansolabehere, S., J.M. de Figueiredo and J.M. Snyder, 2003. "Why is there so little money in U.S. politics?” Journal of Economic Perspectives, 17(1): 105-130.

Akerlof, G. A. 1980. " A Theory of Social Custom, of Which Unemployment May be One Consequence." Quarterly Journal of Economics. 94(4): 749-775.

Austen-Smith, D. 1995. "Campaign contributions and access." American Political Science Review. 89(3), 566-581.

Austen-Smith, D. 1998. "Allocating access for information and contributions." Journal of Law, Economics and Organization. 15(2): 277-303.

Bandiera, O., I. Barnakay, and I. Rasul. 2010. "Social Incentives in the Workplace." Review of Economic Studies. 77: 417-458

Baron, D. 1989. "Service Induced Campaign Contributions and the Electoral Equilibrium." Quarterly Journal of Economics. 104: 45-72.

Bebchuck, L. and R. Jackson. 2010. "Political Speech: Who Decides?” Harvard Law Review. 124: 83-117.

Benabou, R., and J. Tirole. 2006. "Incentives and Prosocial Behavior.” American Economic Review, 96, 1652-1678.

Bernheim, B. D. 1997. "A Theory of Conformity." Journal of Political Economy. 102(5): 841877

Burris, V., 2001. "The two faces of capital: Corporations and individual capitalists as political actors." American Sociological Review, 66: 361-381.

Cameron, A.C. and P.K. Trivedi, 1998. Regression Analysis of Count Data. Cambridge University Press: New York, NY. 
Coates, J.C. IV. 2011. "Corporate Politics, Governance, and Value Before and After Citizens United” Working Paper Available at SSRN: http://ssrn.com/abstract=1973771.

Center for Responsive Politics. 2011. OpenSecrets.org. www.opensecrets.org, last accessed December 20, 2011.

Chan, W. 1996. "External Recruitment versus Internal Promotion,” Journal of Labor Economics, 14(4), 555-570.

Chappell, H.W. Jr. 1982. "Campaign Contributions and Congressional Voting: A Simultaneous Probit-Tobit Model." Review of Economics and Statistics. 62(1): 77-83.

Cotton, C. Forthcoming. "Pay-to-play politics: Informational lobbying and campaign finance reform when contributions buy access." Journal of Public Economics.

Cremer, J. 1986. "Cooperation in Ongoing Organizations," The Quarterly Journal of Economics, 101(1), 33-50.

Durden, G. C., and J.J . Silberman. 1976. "Determining Legislative Preferences for the Minimum Wage: An Economic Approach," Journal of' Political Economy 84: 317-329.

Fama, E. F. 1980. "Agency Problems and the Theory of the Firm." Journal of Political Economy. 88(2), 288-307

Federal Elections Commission (FEC), February 28, 2007. MUR 5487 Conciliation Agreement. Available online at: http://eqs.nictusa.com/eqsdocsMUR/00005AA7.pdf

Federal Elections Commission (FEC), February 2011. "The FEC and the Federal Campaign Finance Law." http://www.fec.gov/pages/brochures/fecfeca.shtml. Last accessed December 20, 2011.

Fracassi, C., and G. Tate. 2012. "External Networking and Internal Firm Governance.” Journal of Finance. Forthcoming.

Francia, P. L., Green, J. C., Herrnson, P. S., Powell, L. W., and Wilcox, C., 2003. The financiers of Congressional elections: Investors, ideologues, and intimates. New York: Columbia University Press.

Gordon, S.C., C. Hafer and D. Landa, 2007. "Consumption or investment? On motivations for political giving." Journal of Politics, 69(4): 1057-1072.

Gibbons, R., and K.J. Murphy. 1992. "Optimal Incentive Contracts in the Presence of Career Concerns: Theory and Evidence.” Journal of Political Economy. 100: 468-505.

Grenzke, J. M. 1989. "PACS and the Congressional Supermarket: The Currency is Complex." American Journal of Political Science. 33: 1-24.

Grier, K. B., M.C. Munger, and B. E. Roberts. 1994. "The Determinants of Industry Political Activity, 1978-1994.” American Political Science Review. 88(4): 911-926.

Gupta, S., and C. W. Swenson. 2003. "Rent Seeking by Agents of the Firm." Journal of Law and Economics. 46(1): 253-268. 
Guthey, E., and B. Jackson. 2005. CEO portraits and the authenticity paradox. Journal of Management Studies. 42(5): 1058-1082.

Hillman, A.J., G.D. Keim and D. Schuler, 2004. "Corporate political activity: A review and research agenda." Journal of Management, 30(6): 837-857.

Joulfaian, D. and M.L. Marlow. 1991. "Incentives and political contributions." Public Choice. 69: 351-355.

Kaplan, S.N. and B.A. Minton, 2006. "How has CEO turnover changed? Increasingly performance sensitive boards and increasingly uneasy CEOs." NBER Working Paper 12465.

Kaplan, S.N., M. Klebanov, and M. Sorenson. 2012. "Which CEO Characteristics and Abilities Matter." Journal of Finance. Forthcoming.

Keim, G., and A. Zardkoohi. 1988. "Looking for Leverage in PAC Markets: Corporate and Labor Contributions Considered." Public Choice 58:21-34.

Kroszner, R. S., and T. Stratmann. 1998. "Interest-Group Competition and the Organization of Congress: Theory and Evidence from Financial Services' Political Action Committees." American Economic Review, 88(5) 1163-1187

Meer, J. 2011. "Brother, Can You Spare a Dime: Peer Pressure in Charitable Solicitation." Journal of Public Economics. 95(7-8): 926-941.

Meer, J. and H.S. Rosen. 2011. "The ABCs of Charitable Solicitation." Journal of Public Economics. 95(5-6): 363-371.

Milyo, J., D. Primo, and T. Groseclose. 2000. "Corporate PAC Campaign Contributions in Perspective," Business and Politics: Vol. 2: Iss. 1, Article 5.

Ovtchinnikov, A. V., and E. Pantaleoni. Forthcoming. "Individual Political Contributions and Firm Performance." Journal of Financial Economics.

Prendergast, C. 1993. “A Theory of 'Yes Men'.” American Economic Review: 83(4): 757-770.

Snyder, J. M. 1990. "Campaign Contributions as Investments: The U.S. House of Representatives, 1980-1986." Journal of Political Economy. 98(6), 1195-1227.

Stratmann, T. 1995. "Campaign Contributions and Congressional Voting: Does the Timing of Contributions Matter?" Review of Economics and Statistics. 72(1): 85-114.

Stratmann, T. 1998. "The Market for Congressional Votes: Is the Timing of Contributions Everything?" Journal of Law and Economics. 41: 85-114.

Tate, G., and U. Malmendier. 2009. "Superstar CEOs.” Quarterly Journal of Economics. 124(4): 1593-1638

Wright, J.R. 1990. "Contributions, Lobbying, and Committee Voting in the U.S. House of Representatives." American Political Science Review. 84: 417-438. 


\section{Figures and Tables}

Figure 1 - Giving Patterns of Representative Individuals who held Leadership Positions at Different Types of Organizations (Labor Union, Non-Profit, and Business)

Panel A - Labor Union Leader

President of the National Air Traffic Controllers Association Sep '97 - Sep '00 (shaded)

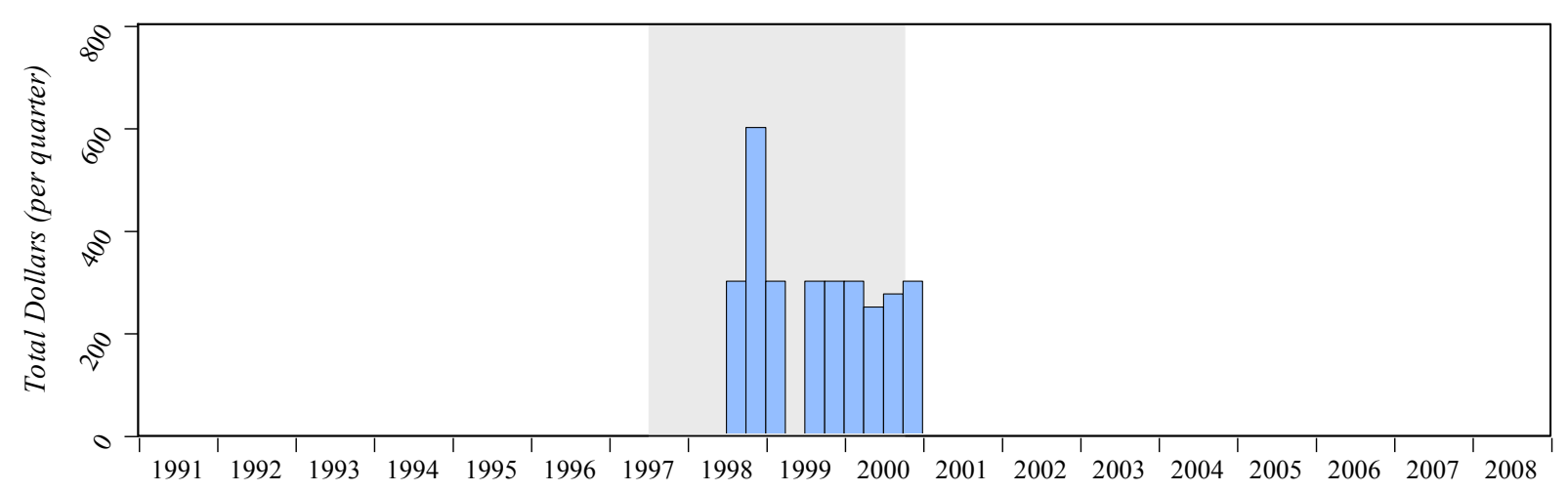

Panel B - Non-Profit Leader

Campaign Contributions made by Reynold Levy

President of Lincoln Center for Performing Arts, Mar '02 - Pres. (shaded)

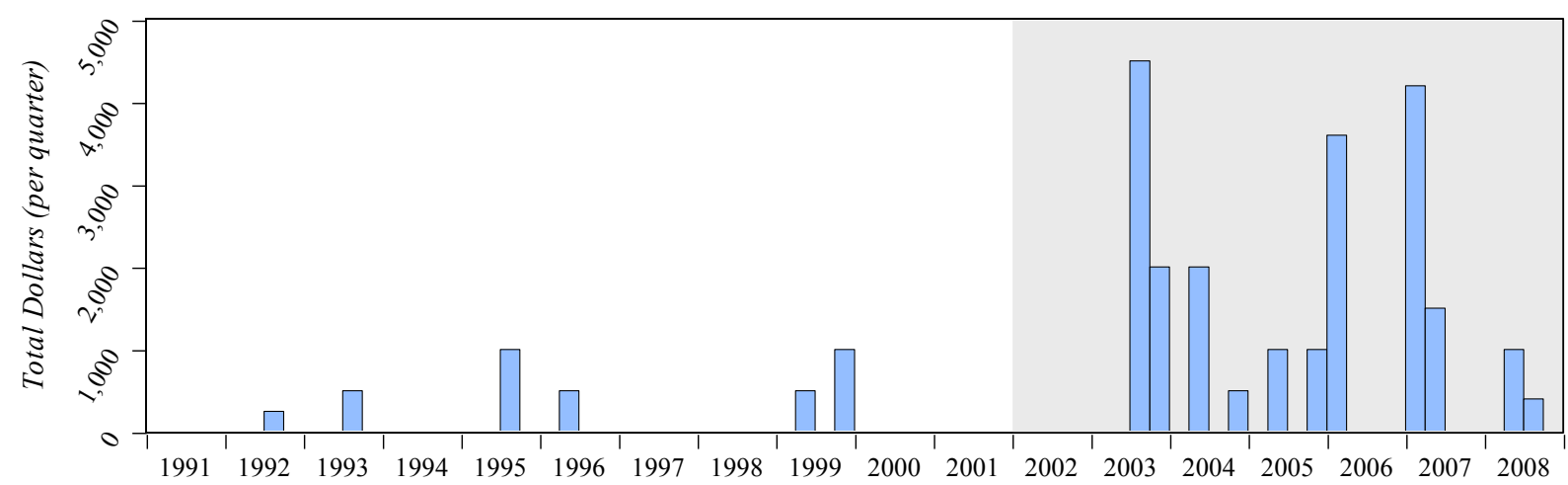

Panel C-Business Leader

Campaign Contributions made by Paul M. Anderson CEO of PanEnergy, Apr '95 - Mar '98; CEO of Duke Energy, Nov '03 - Jan '07 (shaded)

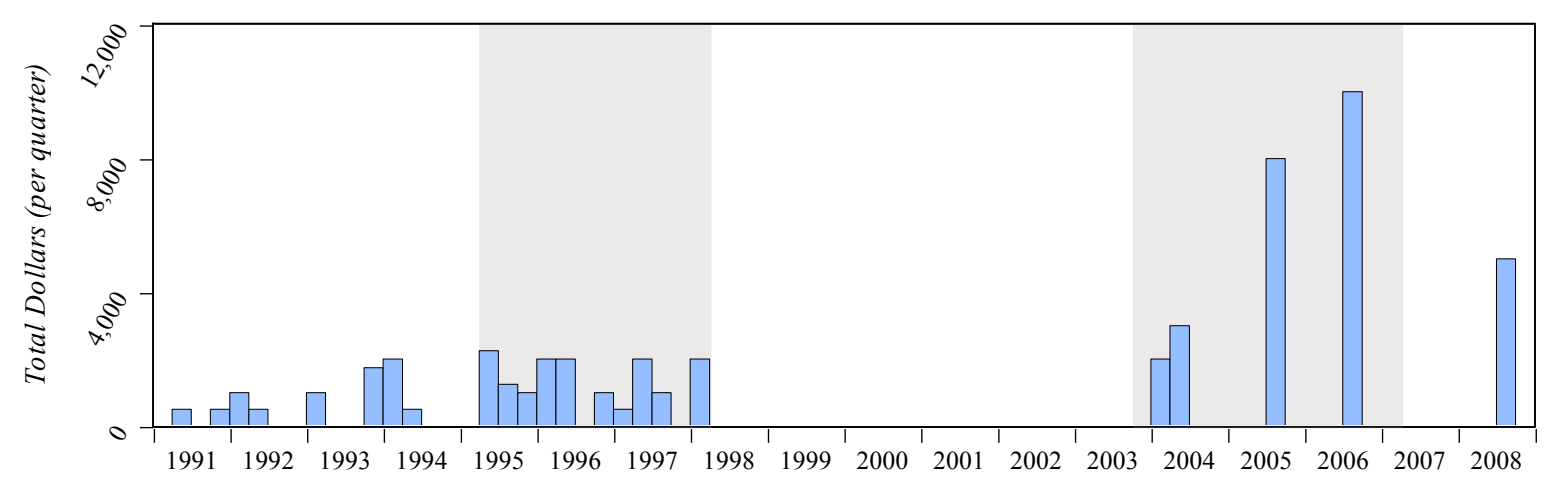


Figure 2 - Distribution of Personal Campaign Contributions by Individuals' Current Career Phase Data

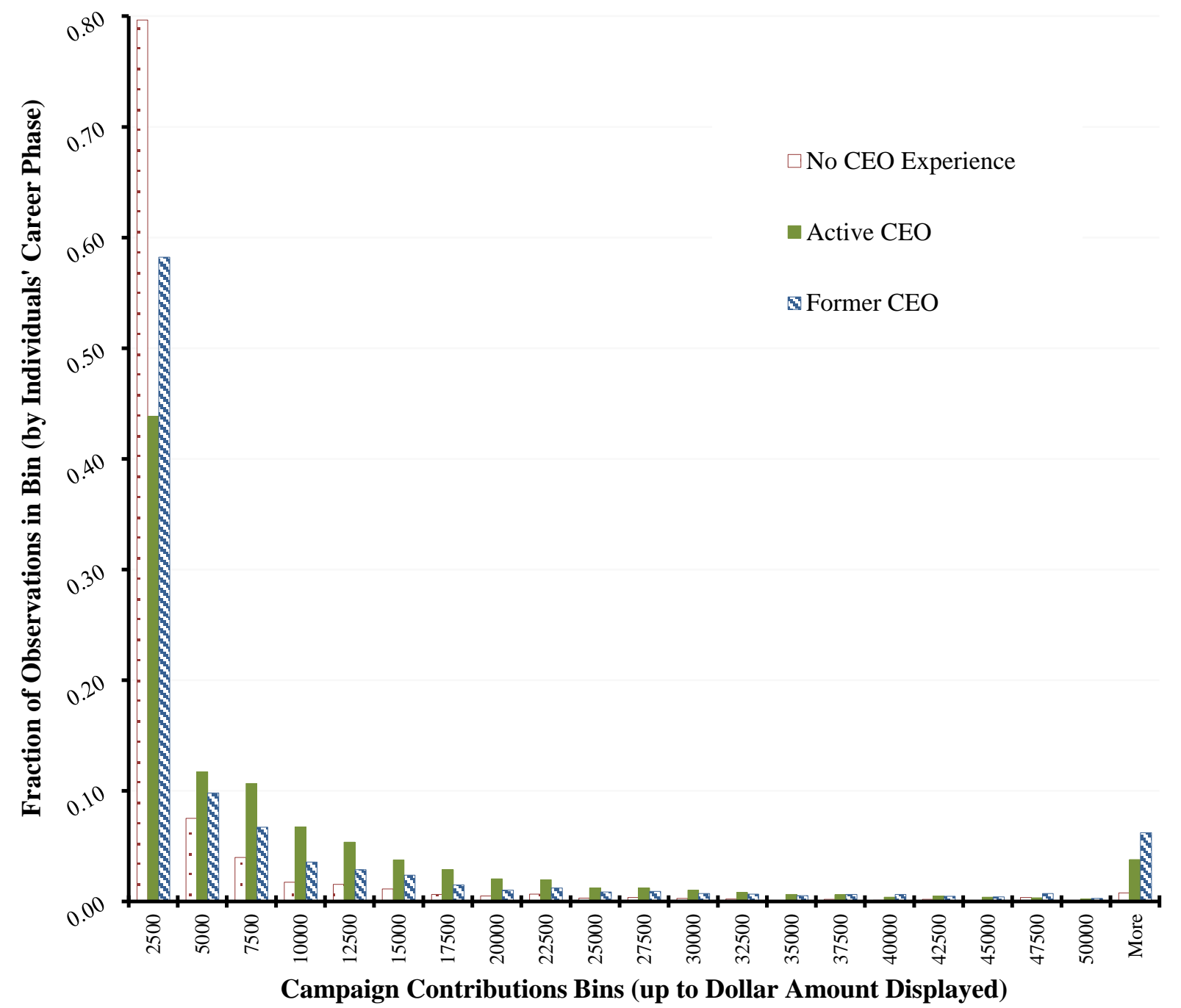


Figure 3 - Mean of Individuals' Contributions by Career Phases across Election Cycles

Panel A - Raw Data

Mean Dollar Amount of Personal Campaign Contributions by Individuals in Different Career Phases across Election Cycles from 1992-2008

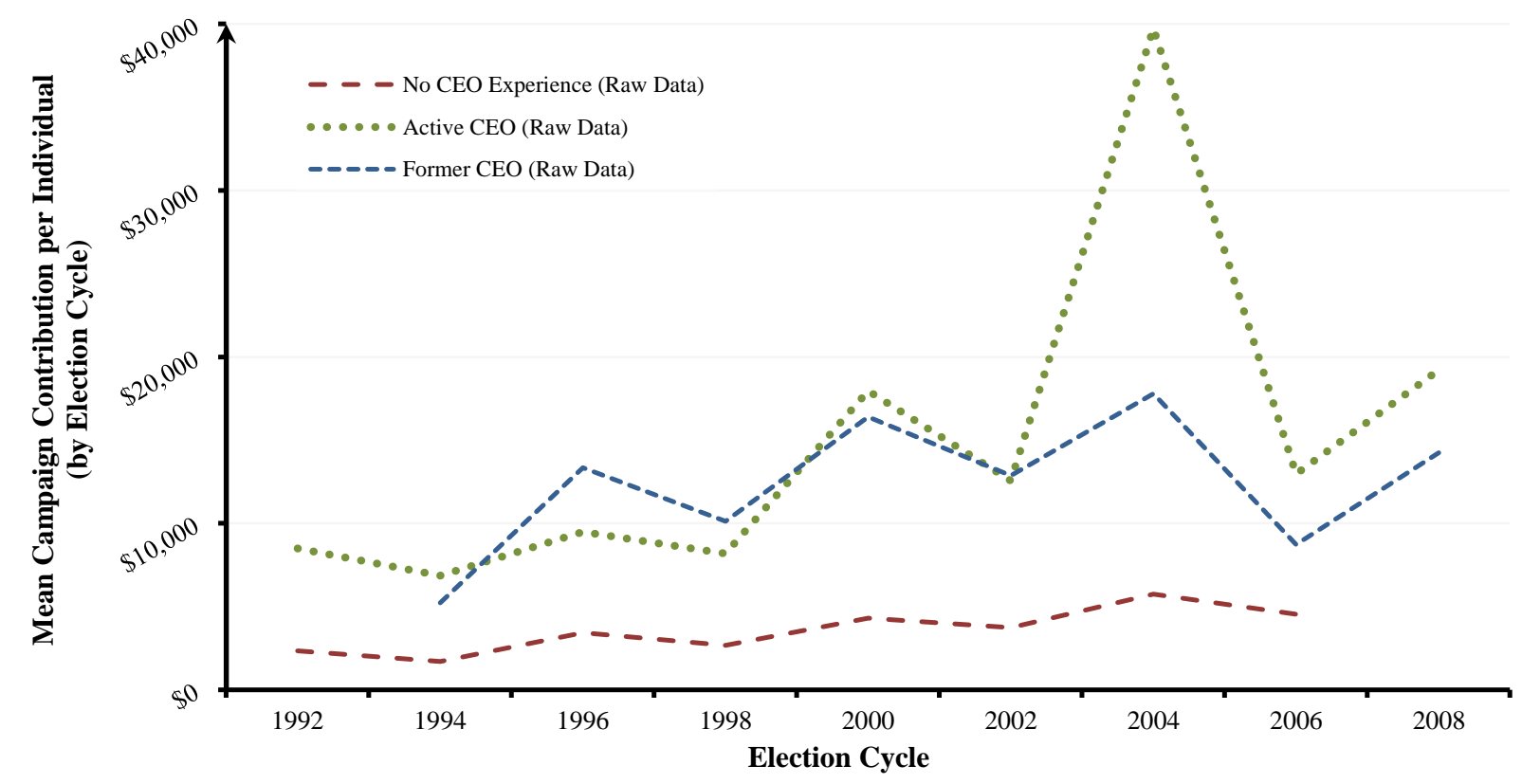

Panel B - Restricted Data (Winsorizing Anomalous Entries)

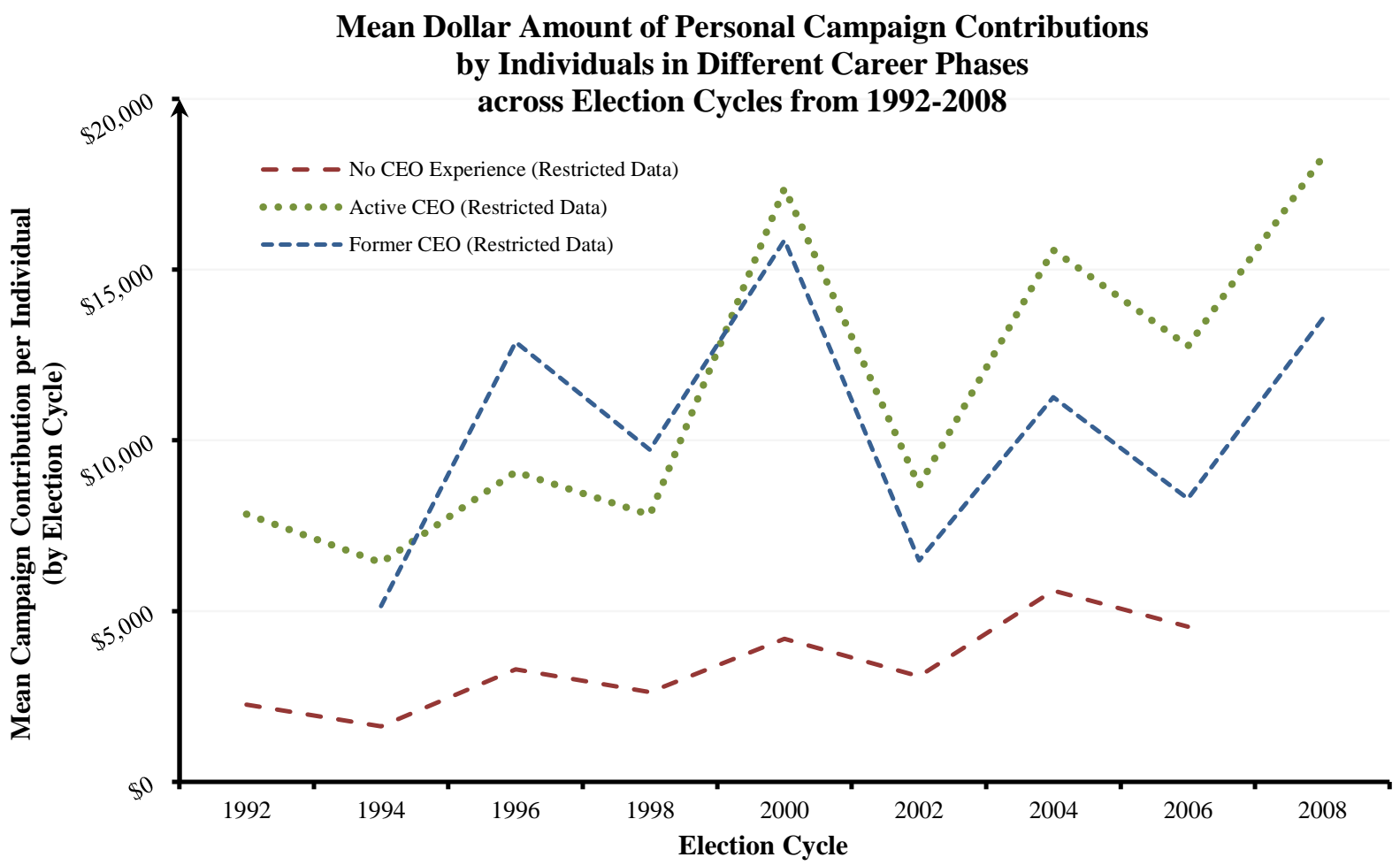


Table 1 - Legal Limits on Campaign Contributions

\begin{tabular}{|c|c|c|c|c|c|c|c|c|c|c|c|}
\hline Period & & $\begin{array}{l}\text { Individual } \\
\text { Candidates }\end{array}$ & & $\begin{array}{l}\text { Candidates } \\
\text { Aggregate }\end{array}$ & & $\begin{array}{l}\text { Individual } \\
\text { PACs }\end{array}$ & & $\begin{array}{c}\text { To Party } \\
\text { Cmtes }\end{array}$ & & $\begin{array}{l}\text { To PACs \& } \\
\text { arty Cmtes } \\
\text { Combined }\end{array}$ & $\begin{array}{c}\text { Aggregate } \\
\text { Limit }\end{array}$ \\
\hline $1974-2002$ & $\$$ & $1,000.00$ & & - & $\$$ & $5,000.00$ & $\$$ & $20,000.00$ & & - & $25,000.00$ \\
\hline $2002-2004$ & $\$$ & $2,000.00$ & $\$$ & $37,500.00$ & $\$$ & $5,000.00$ & $\$$ & $25,000.00$ & $\$$ & $57,500.00$ & $95,000.00$ \\
\hline $2005-2006$ & $\$$ & $2,100.00$ & $\$$ & $40,000.00$ & $\$$ & $5,000.00$ & $\$$ & $26,700.00$ & $\$$ & $61,400.00$ & $\$ 101,400.00$ \\
\hline $2007-2008$ & $\$$ & $2,300.00$ & $\$$ & $42,700.00$ & $\$$ & $5,000.00$ & $\$$ & $28,500.00$ & $\$$ & $65,500.00$ & $\$ 108,200.00$ \\
\hline 2009-2010 & $\$$ & $2,400.00$ & $\$$ & $45,600.00$ & $\$$ & $5,000.00$ & $\$$ & $30,400.00$ & $\$$ & $69,900.00$ & $\$ 115,500.00$ \\
\hline
\end{tabular}

1. Prior to 2002, "soft money" contributions allowed individuals to execced the limit to party committees and hence aggregate limits.

2. The change in 2002 is the result of McCain Feingold, which is why it evolves in later period as it was benchmarked to an inflation metric 
Table 2: Summary Statistics for Campaign Contributions of Individuals who were the CEO of an S\&P 500 firm at any point during the 1991-2008 period

\begin{tabular}{|c|c|c|}
\hline \\
\hline Number of election cycles (1991-2008) & & \\
\hline Number of individual S\&P 500 CEOs & & 2,198 \\
\hline Number of firms & & 949 \\
\hline Average tenure of S\&P 500 CEO (no. of election cycles) & & 2.94 \\
\hline & Per Cycle & All Cycles \\
\hline Share of Individuals who: & & \\
\hline Made any contribution & $55.9 \%$ & $89.4 \%$ \\
\hline Contributed to candidates & $47.8 \%$ & $86.1 \%$ \\
\hline Contributed to PACs & $29.4 \%$ & $72.7 \%$ \\
\hline Contributed to party committees & $22.1 \%$ & $63.6 \%$ \\
\hline Of Individuals that gave to a candidate, share that contrit & & \\
\hline Republicans & $82.0 \%$ & $93.7 \%$ \\
\hline Democrats & $54.7 \%$ & $78.5 \%$ \\
\hline Independents & $1.4 \%$ & $6.9 \%$ \\
\hline Both parties within the same cycle & $37.9 \%$ & $64.2 \%$ \\
\hline Both parties across any cycle & & $72.5 \%$ \\
\hline Only to Republicans & $44.6 \%$ & $21.3 \%$ \\
\hline Only to Democrats & $17.4 \%$ & $6.1 \%$ \\
\hline Only to Independents & $0.2 \%$ & $0.1 \%$ \\
\hline Of Individuals that gave to party committees, share that $c$ & & \\
\hline Republican & $78.5 \%$ & $85.1 \%$ \\
\hline Democrat & $28.7 \%$ & $40.5 \%$ \\
\hline Independent & $0.3 \%$ & $0.8 \%$ \\
\hline Both parties within the same cycle & $7.5 \%$ & $16.5 \%$ \\
\hline Both parties across any cycle & & $26.6 \%$ \\
\hline Only to Republicans & $71.1 \%$ & $59.2 \%$ \\
\hline Only to Democrats & $21.3 \%$ & $14.3 \%$ \\
\hline Only to Independents & $0.2 \%$ & $0.2 \%$ \\
\hline Of Individuals that gave to PACs, share that contributed & & \\
\hline Business & $85.0 \%$ & $91.7 \%$ \\
\hline Ideology & $29.5 \%$ & $50.8 \%$ \\
\hline Labor & $0.2 \%$ & $0.3 \%$ \\
\hline Other/unknown & $0.4 \%$ & $1.4 \%$ \\
\hline
\end{tabular}

\begin{tabular}{lrrr}
\hline Career Phase of Individual: & $\begin{array}{c}\text { No Experience as } \\
\text { S\&P 500 CEO }\end{array}$ & $\begin{array}{c}\text { Active S\&P 500 } \\
\text { CEO }\end{array}$ & $\begin{array}{c}\text { Former S\&P 500 } \\
\text { CEO }\end{array}$ \\
\hline Mean & Total Contribution Levels $(\$)$ & \\
Median & 3,075 & 15,115 & 13,116 \\
Standard deviation & 0 & 4,000 & 1,000 \\
Minimum & 16,313 & 118,040 & 75,280 \\
Maximum & $-9,178$ & $-31,300$ & $-10,000$ \\
& 716,000 & $6,864,978$ & $3,863,313$ \\
\hline Mean & Total Number of Contribution Recipients $($ Count $)$ \\
Median & 1.46 & 4.25 & 3.14 \\
Standard deviation & 0 & 3 & 1 \\
Minimum & 3.17 & 5.58 & 5.47 \\
Maximum & 0 & 0 & 0 \\
Number of individual/election-cycle observations & 50 & 50 & 50 \\
\hline \hline Notes: & 7,124 & 6,658 & 5,999 \\
\hline
\end{tabular}

Notes:

1. Former CEOs include individuals who, at some point, were a CEO of an S\&P 500 firm, but are not for this particular election cycle. It is possible that these individuals will be a CEO in future cycle. 
Table 3: Effect of Becoming CEO of an S\&P500 Firm on the Dollar Amount of Political Contributions Given

\begin{tabular}{|c|c|c|c|c|c|c|c|c|}
\hline \multirow{3}{*}{ Dependent Variable: } & \multicolumn{2}{|c|}{$\overline{\mathrm{I}}$} & \multicolumn{2}{|c|}{$\overline{\mathrm{II}}$} & \multicolumn{2}{|c|}{ 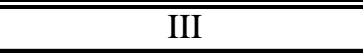 } & \multicolumn{2}{|c|}{ 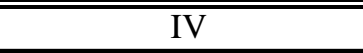 } \\
\hline & \multicolumn{8}{|c|}{ Total Contribution Amounts in Dollars } \\
\hline & Coef. & Std.Err. & Coef. & Std.Err. & Coef. & Std.Err. & Coef. & Std.Err. \\
\hline$\overline{\mathrm{CEO}}$ & $3700.9 *$ & 1944.7 & $2451.5 * * *$ & 237.1 & $3776.2 * * *$ & 566.3 & $5759.2 * * *$ & 1551.8 \\
\hline Former CEO & -616.6 & 2916.3 & -518.5 & 355.9 & 1342.1 & 849.2 & 2126.8 & 2299.7 \\
\hline Individual Fixed Effects & \multicolumn{2}{|c|}{ Yes } & \multicolumn{2}{|c|}{ Yes } & \multicolumn{2}{|c|}{ Yes } & \multicolumn{2}{|c|}{ Yes } \\
\hline Election Cycle Fixed Effects & \multicolumn{2}{|c|}{ Yes } & \multicolumn{2}{|c|}{ Yes } & \multicolumn{2}{|c|}{ Yes } & \multicolumn{2}{|c|}{ Yes } \\
\hline Estimator & \multicolumn{2}{|c|}{ Within } & \multicolumn{2}{|c|}{ Within } & \multicolumn{2}{|c|}{ Within } & \multicolumn{2}{|c|}{ Within } \\
\hline Sample Restriction & \multicolumn{2}{|c|}{ None } & \multicolumn{2}{|c|}{$\begin{array}{l}\text { Drop Negative and Over } \\
\text { Legal Limit Observations }\end{array}$} & \multicolumn{2}{|c|}{ None } & \multicolumn{2}{|c|}{$\begin{array}{l}\text { Drop Individuals who } \\
\text { enter the Dataset as CEO }\end{array}$} \\
\hline $\begin{array}{l}\text { Transformation of Dependent } \\
\text { Variable }\end{array}$ & \multicolumn{2}{|c|}{ None } & \multicolumn{2}{|c|}{ None } & \multicolumn{2}{|c|}{$\begin{array}{l}\text { Set Negatives to Zero, } \\
\text { Over-Limit to Limit }\end{array}$} & \multicolumn{2}{|c|}{ None } \\
\hline F-stat. & \multicolumn{2}{|c|}{$2.19 * * *$} & \multicolumn{2}{|c|}{$8.30 * * *$} & \multicolumn{2}{|c|}{$6.55 * * *$} & \multicolumn{2}{|c|}{$2.66 * * *$} \\
\hline $\mathrm{N}$ & \multicolumn{2}{|c|}{19782} & \multicolumn{2}{|c|}{19078} & \multicolumn{2}{|c|}{19782} & & \\
\hline & & & & & $\bar{V}$ & & & \\
\hline Dependent Variable: & $\begin{array}{l}\text { Total Co } \\
\text { Amounts }\end{array}$ & $\begin{array}{l}\text { ibution } \\
\text { Dollars }\end{array}$ & $\begin{array}{r}\text { Total Co } \\
\text { Amounts } i \\
\text { Cand }\end{array}$ & $\begin{array}{l}\text { ibution } \\
\text { ollars to } \\
\text { ates }\end{array}$ & $\begin{array}{r}\text { Total Con } \\
\text { Am ounts in } \\
P A\end{array}$ & $\begin{array}{l}\text { ibution } \\
\text { Dollars to }\end{array}$ & $\begin{array}{r}\text { Total Co } \\
\text { Amounts } i \\
\mathrm{~Pa}\end{array}$ & $\begin{array}{l}\text { ibution } \\
\text { Dollars to } \\
\text { es }\end{array}$ \\
\hline & Coef. & Std.Err. & Coef. & Std.Err. & Coef. & Std.Err. & Coef. & Std.Err. \\
\hline$\overline{\mathrm{CEO}}$ & $4028.6^{* * *}$ & 528.2 & $885.4 * * *$ & 103.3 & $1136.6 * * *$ & 148.4 & $1838.5^{* * *}$ & 464.3 \\
\hline Former CEO & -714.0 & 782.7 & $-503.3 * * *$ & 153.1 & $-1069.8 * * *$ & 219.9 & 585.3 & 688.1 \\
\hline Individual Fixed Effects & & & & & $\mathrm{Y}$ & & & \\
\hline Election Cycle Fixed Effects & & & & & $\mathrm{Y}$ & & & \\
\hline Estimator & & & & & Wit & & & \\
\hline Sample Restriction & $\begin{array}{l}\text { Drop Indi } \\
\text { enter the D }\end{array}$ & $\begin{array}{l}\text { uals who } \\
\text { et as CEO }\end{array}$ & $\begin{array}{l}\text { Drop Indi } \\
\text { enter the Di }\end{array}$ & $\begin{array}{l}\text { uals who } \\
\text { set as CEO }\end{array}$ & $\begin{array}{l}\text { Drop Indiv } \\
\text { enter the Dat }\end{array}$ & $\begin{array}{l}\text { uals who } \\
\text { set as CEO }\end{array}$ & $\begin{array}{l}\text { Drop Indi } \\
\text { enter the D }\end{array}$ & $\begin{array}{l}\text { luals who } \\
\text { set as CEO }\end{array}$ \\
\hline $\begin{array}{l}\text { Transformation of Dependent } \\
\text { Variable }\end{array}$ & $\begin{array}{r}\text { Set Negat } \\
\text { Over-Lir }\end{array}$ & $\begin{array}{l}\text { to Zero, } \\
\text { to Limit }\end{array}$ & $\begin{array}{l}\text { Set Negati } \\
\text { Over-Lin }\end{array}$ & $\begin{array}{l}\text { s to Zero, } \\
\text { to Limit }\end{array}$ & $\begin{array}{l}\text { Set Negativ } \\
\text { Over-Lim }\end{array}$ & $\begin{array}{l}\text { s to Zero, } \\
\text { to Limit }\end{array}$ & $\begin{array}{l}\text { Set Negat } \\
\text { Over-Lir }\end{array}$ & $\begin{array}{l}\text { s to Zero, } \\
\text { to Limit }\end{array}$ \\
\hline F-stat. & 6.7 & & 10.1 & & 4.32 & & 4.3 & \\
\hline $\mathrm{N}$ & & & & & 140 & & & \\
\hline
\end{tabular}

Notes:

1. ***,**,* indicates significance at $1 \%, 5 \%$ and $10 \%$ levels respectively

2. Former CEO denotes individuals who have previously been CEOs but aren't for a given election cycle. 
Table 4: Effect of Becoming CEO of an S\&P500 on the Intensive and Extensive Margins of Campaign Contribuitons

\begin{tabular}{|c|c|c|c|c|c|c|}
\hline \multirow{3}{*}{ Dependent Variable: } & \multicolumn{2}{|c|}{$\overline{\mathrm{I}}$} & \multicolumn{2}{|c|}{ II } & \multicolumn{2}{|c|}{ III } \\
\hline & \multicolumn{2}{|c|}{$\begin{array}{c}\text { Total Contribution Amounts in } \\
\text { Dollars } \\
\end{array}$} & \multicolumn{2}{|c|}{$\begin{array}{c}\text { Total Contribution Amounts in } \\
\text { Dollars }\end{array}$} & \multicolumn{2}{|c|}{$\begin{array}{c}\text { Total Contribution Amounts in } \\
\text { Dollars }\end{array}$} \\
\hline & Coef. & Std.Err. & Coef. & Std.Err. & Coef. & Std.Err. \\
\hline $\mathrm{CEO}$ & $4950.5^{* * *}$ & 688.5 & $3157.6 * *$ & 1262.6 & $2001.4 * * *$ & 689.3 \\
\hline Former CEO & -1363.0 & 1022.8 & 1582.2 & 1888.3 & 1198.9 & 1014.7 \\
\hline Individual Fixed Effects & \multicolumn{2}{|c|}{ Yes } & \multicolumn{2}{|c|}{ Yes } & \multicolumn{2}{|c|}{ Yes } \\
\hline Election Cycle Fixed Effects & \multicolumn{2}{|c|}{ Yes } & \multicolumn{2}{|c|}{ Yes } & \multicolumn{2}{|c|}{ Yes } \\
\hline Estimator & \multicolumn{2}{|c|}{ Within } & \multicolumn{2}{|c|}{ Within } & \multicolumn{2}{|c|}{ Within } \\
\hline Sample Restriction & \multicolumn{2}{|c|}{$\begin{array}{c}\text { Contributions Prior to Becoming } \\
\text { CEO }\end{array}$} & \multicolumn{2}{|c|}{$\begin{array}{l}\text { Contribute Prior to Becoming } \\
\text { CEO, but Gave After }\end{array}$} & \multicolumn{2}{|c|}{$\begin{array}{l}\text { Contribute Prior to Becoming } \\
\text { CEO }\end{array}$} \\
\hline $\begin{array}{l}\text { Transformation of Dependent } \\
\text { Variable }\end{array}$ & \multicolumn{2}{|c|}{$\begin{array}{l}\text { Set Negatives to Zero, Over- } \\
\text { Limit to Limit }\end{array}$} & \multicolumn{2}{|c|}{$\begin{array}{l}\text { Set Negatives to Zero, Over- } \\
\text { Limit to Limit }\end{array}$} & \multicolumn{2}{|c|}{$\begin{array}{l}\text { Set Negatives to Zero, Over- } \\
\text { Limit to Limit }\end{array}$} \\
\hline F-stat. & \multicolumn{2}{|c|}{$7.10^{* * *}$} & \multicolumn{2}{|c|}{$3.63^{* * *}$} & \multicolumn{2}{|c|}{$3.65 * * *$} \\
\hline Cross-sections Included & \multicolumn{2}{|c|}{1096} & \multicolumn{2}{|c|}{258} & \multicolumn{2}{|c|}{460} \\
\hline $\mathrm{N}$ & \multicolumn{2}{|c|}{9864} & \multicolumn{2}{|c|}{2322} & \multicolumn{2}{|c|}{4140} \\
\hline
\end{tabular}

Notes:

1. ***,**,* indicates significance at $1 \%, 5 \%$ and $10 \%$ levels respectively

2. Former CEO denotes individuals who have previously been CEOs but aren't for a given election cycle. 


\begin{tabular}{|c|c|c|c|c|c|c|c|c|}
\hline \multirow{3}{*}{ Dependent Variable: } & \multicolumn{2}{|c|}{ 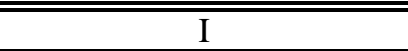 } & \multicolumn{2}{|c|}{$\overline{\mathrm{III}}$} & \multicolumn{2}{|c|}{ 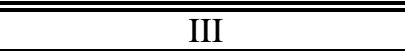 } & \multicolumn{2}{|c|}{ IV } \\
\hline & \multicolumn{2}{|c|}{$\begin{array}{c}\text { Total Unique Contribution } \\
\text { Recipients }\end{array}$} & \multicolumn{2}{|c|}{$\begin{array}{c}\text { Contributions to Unique } \\
\text { Candidates }\end{array}$} & \multicolumn{2}{|c|}{$\begin{array}{c}\text { Contributions to Unique } \\
\text { PACs }\end{array}$} & \multicolumn{2}{|c|}{$\begin{array}{c}\text { Contributions to Unique } \\
\text { Party Committees }\end{array}$} \\
\hline & Coef. & Std.Err. & Coef. & Std.Err. & Coef. & Std.Err. & Coef. & Std.Err. \\
\hline$\overline{\mathrm{CEO}}$ & $0.339 * * *$ & 0.030 & $0.294 * * *$ & 0.035 & $0.402 * * *$ & 0.046 & $0.347 * * *$ & 0.065 \\
\hline Former CEO & $-0.562 * * *$ & 0.046 & $-0.542 * * *$ & 0.052 & $-0.628 * * *$ & 0.075 & $-0.185^{*}$ & 0.097 \\
\hline Individual Fixed Effects & \multicolumn{2}{|c|}{ Yes } & \multicolumn{2}{|c|}{ Yes } & \multicolumn{2}{|c|}{ Yes } & \multicolumn{2}{|c|}{ Yes } \\
\hline Election Cycle Fixed Effects & \multicolumn{2}{|c|}{ Yes } & \multicolumn{2}{|c|}{ Yes } & \multicolumn{2}{|c|}{ Yes } & \multicolumn{2}{|c|}{ Yes } \\
\hline Distribution & \multicolumn{2}{|c|}{ Negative Binomial } & \multicolumn{2}{|c|}{ Negative Binomial } & \multicolumn{2}{|c|}{ Negative Binomial } & \multicolumn{2}{|c|}{ Negative Binomial } \\
\hline Sample Restriction & \multicolumn{2}{|c|}{$\begin{array}{l}\text { Drop Individuals who enter } \\
\text { the Dataset as CEO }\end{array}$} & \multicolumn{2}{|c|}{$\begin{array}{l}\text { Drop Individuals who enter } \\
\text { the Dataset as CEO }\end{array}$} & \multicolumn{2}{|c|}{$\begin{array}{l}\text { Drop Individuals who enter } \\
\text { the Dataset as CEO }\end{array}$} & \multicolumn{2}{|c|}{$\begin{array}{l}\text { Drop Individuals who enter } \\
\text { the Dataset as CEO }\end{array}$} \\
\hline Log Likelihood & \multicolumn{2}{|c|}{-19930.89} & \multicolumn{2}{|c|}{-16158.47} & \multicolumn{2}{|c|}{-8219.36} & \multicolumn{2}{|c|}{-6743.97} \\
\hline $\mathrm{N}$ & \multicolumn{2}{|c|}{14004} & \multicolumn{2}{|c|}{14004} & \multicolumn{2}{|c|}{14004} & \multicolumn{2}{|c|}{14004} \\
\hline
\end{tabular}

1. ***,**,* indicates significance at $1 \%, 5 \%$ and $10 \%$ levels respectively

2. Former CEO denotes individuals who have previously been CEOs but aren't for a given election cycle. 
Table 6: Effect of Becoming an S\&P 500 CEO on the Partisianship of Political Contributions

\begin{tabular}{|c|c|c|c|c|c|c|}
\hline \multirow{3}{*}{ Dependent Variable: } & \multicolumn{2}{|c|}{$\overline{\mathrm{I}}$} & \multicolumn{2}{|c|}{$\overline{\mathrm{II}}$} & \multicolumn{2}{|c|}{ 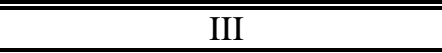 } \\
\hline & \multicolumn{6}{|c|}{ Fraction of Contributions in Dollars to Parties that are Republican } \\
\hline & Coef. & Std.Err. & Coef. & Std.Err. & Coef. & Std.Err. \\
\hline$\overline{\mathrm{CEO}}$ & $-0.037 * *$ & 0.017 & -0.030 & 0.021 & $-0.049 * *$ & 0.023 \\
\hline Former CEO & $-0.046^{*}$ & 0.024 & -0.038 & 0.029 & $-0.067 * *$ & 0.033 \\
\hline Individual Fixed Effects & \multicolumn{2}{|c|}{ Yes } & \multicolumn{2}{|c|}{ Yes } & \multicolumn{2}{|c|}{ Yes } \\
\hline Election Cycle Fixed Effects & \multicolumn{2}{|c|}{ Yes } & \multicolumn{2}{|c|}{ Yes } & \multicolumn{2}{|c|}{ Yes } \\
\hline Estimator & \multicolumn{2}{|c|}{ Within } & \multicolumn{2}{|c|}{ Within } & \multicolumn{2}{|c|}{ Within } \\
\hline Sample Restriction & \multicolumn{2}{|c|}{ None } & \multicolumn{2}{|c|}{$\begin{array}{c}\text { Drop Negative or Over Aggregate } \\
\text { Legal Limit Observations }\end{array}$} & \multicolumn{2}{|c|}{$\begin{array}{c}\text { Drop Individuals who enter the } \\
\text { Dataset as CEO }\end{array}$} \\
\hline Transformation of Dependent Variable & \multicolumn{2}{|c|}{ None } & \multicolumn{2}{|c|}{ None } & \multicolumn{2}{|c|}{ None } \\
\hline F-stat. & \multicolumn{2}{|c|}{$7.18 * * *$} & \multicolumn{2}{|c|}{$5.09 * * *$} & \multicolumn{2}{|c|}{$5.56 * * *$} \\
\hline $\mathrm{N}$ & \multicolumn{2}{|c|}{4656} & \multicolumn{2}{|c|}{3756} & \multicolumn{2}{|c|}{2605} \\
\hline \multirow{3}{*}{ Dependent Variable: } & & & & & & \\
\hline & \multicolumn{6}{|c|}{ Fraction of Contributions in Dollars to Candidates who are Republican } \\
\hline & Coef. & Std.Err. & Coef. & Std.Err. & Coef. & Std.Err. \\
\hline$\overline{\mathrm{CEO}}$ & -0.009 & 0.011 & -0.007 & 0.012 & 0.003 & 0.014 \\
\hline Former CEO & 0.012 & 0.017 & 0.014 & 0.017 & 0.023 & 0.022 \\
\hline Individual Fixed Effects & \multicolumn{2}{|c|}{ Yes } & \multicolumn{2}{|c|}{ Yes } & \multicolumn{2}{|c|}{ Yes } \\
\hline Election Cycle Fixed Effects & \multicolumn{2}{|c|}{ Yes } & \multicolumn{2}{|c|}{ Yes } & \multicolumn{2}{|c|}{ Yes } \\
\hline Estimator & & & & & & \\
\hline Sample Restriction & & & $\begin{array}{r}\text { Drop Negativ } \\
\text { Legal Liı }\end{array}$ & $\begin{array}{l}\text { er Aggregate } \\
\text { ervations }\end{array}$ & $\begin{array}{r}\text { Drop Indivic } \\
\text { Data }\end{array}$ & $\begin{array}{l}\text { no enter the } \\
\text { EO }\end{array}$ \\
\hline Transformation of Dependent Variable & & & & & & \\
\hline F-stat. & & & & & & \\
\hline $\mathrm{N}$ & & & & & & \\
\hline
\end{tabular}

Notes:

1. ***, **, * indicates significance at $1 \%, 5 \%$ and $10 \%$ levels respectively

2. Former CEO denoted individuals who have previously been CEOs but are not for a given election cycle. 
Table 7: The Effect of Becoming CEO of an S\&P500 Firm on Political Contributions, Adding Potential Ommitted Variables

\begin{tabular}{|c|c|c|c|c|c|c|}
\hline \multirow{3}{*}{ Dependent Variable: } & \multicolumn{2}{|c|}{$\overline{\mathrm{II}}$} & \multicolumn{2}{|c|}{$\overline{\mathrm{II}}$} & \multicolumn{2}{|c|}{$\overline{\text { III }}$} \\
\hline & \multicolumn{6}{|c|}{ Total Contribution Amounts in Dollars } \\
\hline & Coef. & Std.Err. & Coef. & Std.Err. & Coef. & Std.Err. \\
\hline$\overline{\mathrm{CEO}}$ & $1964.8 * * *$ & 575.8 & $2509.4 * * *$ & 563.0 & $3760.7 * * *$ & 534.0 \\
\hline Former CEO & $1805.5^{* *}$ & 830.6 & 660.6 & 801.3 & -1142.6 & 792.9 \\
\hline Salary (Missing Obs. Filled w/ Zeros) & $0.005 * * *$ & 0.001 & & & & \\
\hline Salary (Missing Obs. Filled w/ Min Observed for Indiv.) & & & $0.006 * * *$ & 0.001 & & \\
\hline Salary (Missing Obs. Filled w/ Max Observed for Indiv.) & & & & & $0.002 * * *$ & 0.0006 \\
\hline Individual Fixed Effects & \multicolumn{2}{|c|}{ Yes } & \multicolumn{2}{|c|}{ Yes } & \multicolumn{2}{|c|}{ Yes } \\
\hline Election Cycle Fixed Effects & \multicolumn{2}{|c|}{ Yes } & \multicolumn{2}{|c|}{ Yes } & \multicolumn{2}{|c|}{ Yes } \\
\hline Estimator & \multicolumn{2}{|c|}{ Within } & \multicolumn{2}{|c|}{ Within } & \multicolumn{2}{|c|}{ Within } \\
\hline Sample Restriction & \multicolumn{2}{|c|}{$\begin{array}{l}\text { Drop Individuals who enter } \\
\text { the Dataset as CEO }\end{array}$} & \multicolumn{2}{|c|}{$\begin{array}{l}\text { Drop Individuals who enter } \\
\text { the Dataset as CEO }\end{array}$} & \multicolumn{2}{|c|}{$\begin{array}{l}\text { Drop Individuals who enter } \\
\text { the Dataset as CEO }\end{array}$} \\
\hline Transformation of Dependent Variable & \multicolumn{2}{|c|}{$\begin{array}{l}\text { Set Negatives to Zero, } \\
\text { Over-Limit to Limit }\end{array}$} & \multicolumn{2}{|c|}{$\begin{array}{l}\text { Set Negatives to Zero, } \\
\text { Over-Limit to Limit }\end{array}$} & \multicolumn{2}{|c|}{$\begin{array}{l}\text { Set Negatives to Zero, } \\
\text { Over-Limit to Limit }\end{array}$} \\
\hline F-stat. & \multicolumn{2}{|c|}{$6.843 * * *$} & \multicolumn{2}{|c|}{$6.82 * * *$} & \multicolumn{2}{|c|}{$6.764 * * *$} \\
\hline $\mathrm{N}$ & \multicolumn{2}{|c|}{14004} & \multicolumn{2}{|c|}{14004} & \multicolumn{2}{|c|}{14004} \\
\hline \multirow{3}{*}{ Dependent Variable: } & \multicolumn{2}{|c|}{ IV } & \multicolumn{2}{|c|}{$\overline{\mathrm{V}}$} & \multicolumn{2}{|c|}{ VI } \\
\hline & \multicolumn{6}{|c|}{ Total Contribution Amounts in Dollars } \\
\hline & Coef. & Std.Err. & Coef. & Std.Err. & Coef. & Std.Err. \\
\hline$\overline{\mathrm{CEO}}$ & $3896.4 * * *$ & 530.5 & $1807.0^{* * *}$ & 578.5 & $3610.6^{* * *}$ & 524.0 \\
\hline Former CEO & -834.3 & 783.9 & $1694.0^{* *}$ & 831.3 & -483.6 & 775.7 \\
\hline Salary (Missing Obs. Filled w/ Zeros) & & & $0.005 * * *$ & 0.001 & & \\
\hline \%age of Shares-owned (Missing Obs. Filled w/ Zeros) & $195.1 * *$ & 75.8 & $210.8 * * *$ & 75.6 & & \\
\hline Gave to an Ideological PAC & & & & & $10325.4 * * *$ & 678.8 \\
\hline Individual Fixed Effects & & & & & & \\
\hline Election Cycle Fixed Effects & & & & & & \\
\hline Estimator & & & & & & \\
\hline Sample Restriction & $\begin{array}{r}\text { Drop Indivic } \\
\text { the Data }\end{array}$ & $\begin{array}{l}\text { s who enter } \\
\text { as CEO }\end{array}$ & $\begin{array}{l}\text { Drop Individ } \\
\text { the Datas }\end{array}$ & $\begin{array}{l}\text { ls who enter } \\
\text { as CEO }\end{array}$ & $\begin{array}{l}\text { Drop Individ } \\
\text { the Datas }\end{array}$ & $\begin{array}{l}\text { s who enter } \\
\text { as CEO }\end{array}$ \\
\hline Transformation of Dependent Variable & $\begin{array}{l}\text { Set Negat } \\
\text { Over-Lir }\end{array}$ & $\begin{array}{l}\text { to Zero, } \\
\text { o Limit }\end{array}$ & $\begin{array}{l}\text { Set Negati } \\
\text { Over-Lin }\end{array}$ & $\begin{array}{l}\text { s to Zero, } \\
\text { to Limit }\end{array}$ & $\begin{array}{l}\text { Set Negati } \\
\text { Over-Lin }\end{array}$ & $\begin{array}{l}\text { to Zero, } \\
\text { o Limit }\end{array}$ \\
\hline F-stat. & 6.7 & & 6.8 & *** & 7.02 & \\
\hline $\mathrm{N}$ & & & & & & \\
\hline
\end{tabular}

Notes:

1. ***, **, * indicates significance at $1 \%, 5 \%$ and $10 \%$ levels respectively

2. Former CEO denoted individuals who have previously been CEOs but aren't for a given election cycle. 
Table 8: Falsification Tests of Underlying Idenfication Assumptions

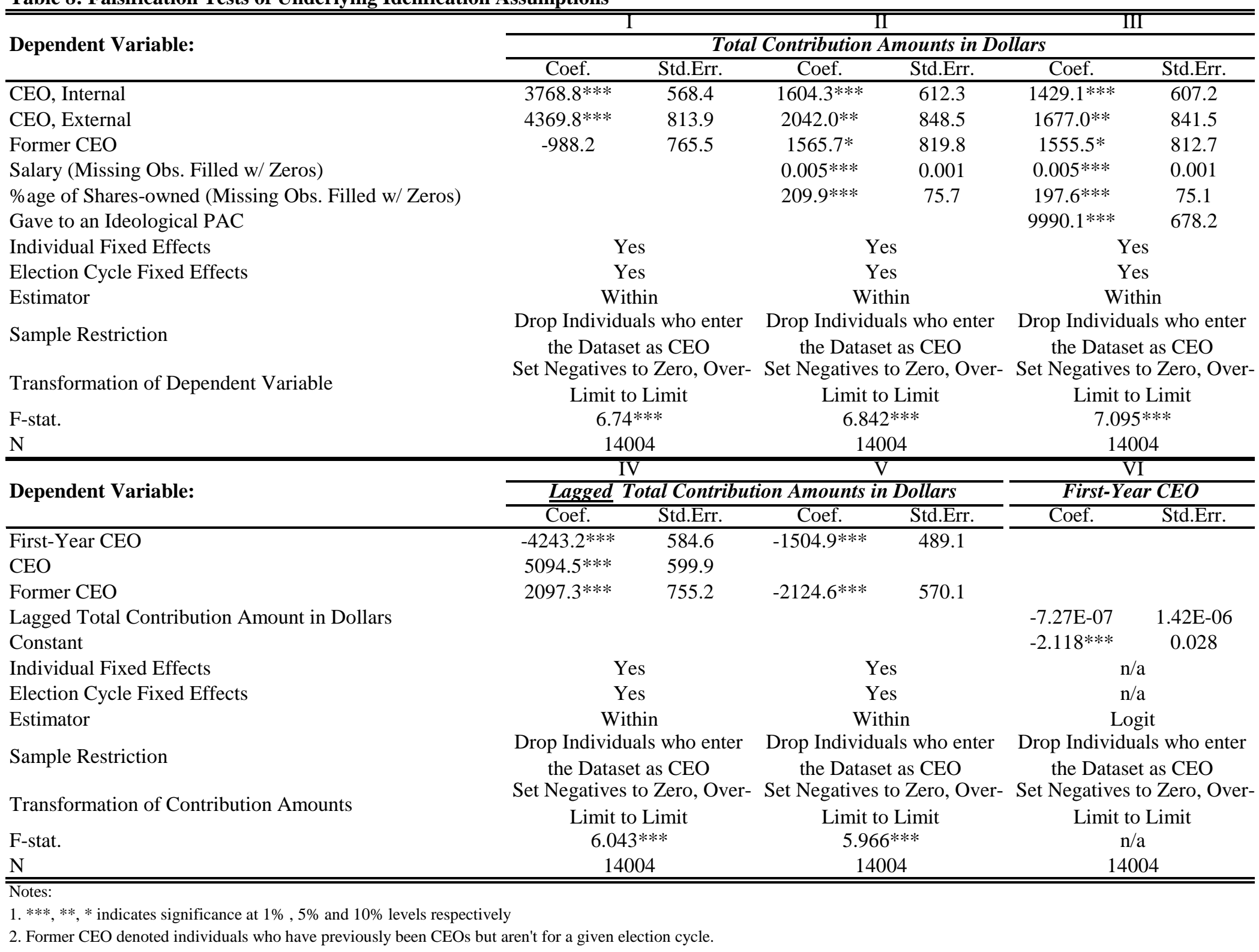

